Research Article

\title{
CFD Numerical Investigation of a New Solar Flat Air-Collector Having Different Obstacles with Various Configurations and Arrangements
}

\author{
Walid Rouissi, ${ }^{1}$ Nabiha Naili, ${ }^{1}$ Mohamed Jarray, ${ }^{2}$ and Majdi Hazami (iD) \\ ${ }^{1}$ Laboratoire Des Procédés Thermiques (LPT), Centre De Recherches Et Des Technologies De L'Energie (CRTEn), PB 95, \\ Hammam Lif 2050, Tunisia \\ ${ }^{2}$ Institut Prime, Département De Génie Mécanique Et Systèmes Complexes, CNRS-Université de Poitiers-ENSMA, \\ Poitiers, France \\ Correspondence should be addressed to Majdi Hazami; hazamdi321@yahoo.fr
}

Received 4 March 2021; Accepted 8 July 2021; Published 15 September 2021

Academic Editor: Gisella Tomasini

Copyright (C) 2021 Walid Rouissi et al. This is an open access article distributed under the Creative Commons Attribution License, which permits unrestricted use, distribution, and reproduction in any medium, provided the original work is properly cited.

\begin{abstract}
This work deals with a numerical parametric optimization study of a new Solar Flat Air Collector (SFAC) configuration. The CFD numerical parametric study investigates various SFAC structures inside the air cavity without obstacles and with spherical, cubic, cylindrical, and pyramidal obstacles. The study optimizes the most convenient configuration and arrangement that allow for the increase of the heat-transfer surface and to make the flow homogeneous in order to generate turbulence zones inside the SFAC air cavity. The result shows that the thermal performances of the cubic form are close to those of the spherical obstacles. Another set of simulations was performed to evaluate the performances of the cubic shape baffles for three orientation angles equal to $0^{\circ}, 22.5^{\circ}$, and $45^{\circ}$, respectively. Each configuration has three forms of arrangement with a relative roughness pitch (b/a) varying between 2 , 4 , and 6 . The results of the simulation study showed that the relative roughness pitch, the Reynolds number, as well as the angle of orientation influence the performance and the operation of the SFAC. The results of the simulations showed that the combination of an orientation of $45^{\circ}$ with a roughness pitch of $\mathrm{b} / \mathrm{a}=2$ increases the SFAC thermal performances, which can reach $85 \%$.
\end{abstract}

\section{Introduction}

The exploitation of renewable energies such as solar energy, which is a clean and inexhaustible source, presents a promising solution against environmental problems and the future exhaustion of fossil fuels. This solar energy can be converted through using solar collectors for the production of thermal energy. The range of application of this thermal energy produced is broad such as drying, heating, or desalination. Given the multiple difficulties that characterize these sensors, such as the presence of dead zones in certain places, thermal losses, and low inertia, various researchers have worked on improving thermal performance on solar collector's air plane. Among the improvements proposed by these researchers are the judicious choice of forms of design parameters (geometric, thermo-physical, and optical), such as the length, the width, and the height of the channel; the thickness of the air space; the glazing; the insulation; and the choice of the absorbing material or the intention to bring back modifications to the absorbing plate. In this context, and according to numerous research studies, the integration of obstacles in the air passage channel presents an effective method for improving the convective heat transfer process by creating turbulence, thereby minimizing dead zones. Indeed, the use of fin types, OT, OIF1, WT, WDL1, and WOL1 [1], and the integrating plus shaped baffles [2] or the planting of triangular, circular, and hexagonal obstructions [3], prove the creation of a turbulent flow, a good distribution of the fluid resulting in the reduction of dead zones. This improves the outlet temperature as well as the efficiency of the collector. For the same purpose, an experimental study carried out by Sompol et al. [4] reveals that the combination 
of engraved grooves and vortex generators which correspond to fins in the delta form with holes in the middle placed on the plate of the absorber with a very precise ratio of fin area and hole area with an angle of attack equal to $45^{\circ}$, provides the greatest number of Nusselt, and gives a friction factor around 6 and 30 times greater in the case of smooth channel. The technique of using a multi-pass solar collector gives rather important results for the improvement of yield. Using numerical and experimental analysis, Doğuş Tuncer et al. [5] showed that heat transfer can be improved by dividing the interior of the solar collector channel into four parts. They reported that this quadruple pass sensor (QPSAC) used for drying can achieve an average thermal efficiency equal to $80.66 \%$ considered efficient compared to ordinary collector and can reduce the drying time. In this context, the form and the geometry of the solar collector can enhance its thermal performance as proposed by Singh [6]. This method consists of making a double pass model containing three in-lines, offset, and hybrid fin shapes. These models are digitally studied (CFD) and prove that these types of fins offer better thermo-hydraulic performance which can reach $79 \%, 13 \%$ more than a single air passage design. The change of the internal structure by increasing the residence time of the air, considerably improves the thermal efficiency. $\mathrm{Hu}$ et al. [7] conducted experimental and numerical studies to highlight the influence of the installation of internal deflectors on the prolongation of the residence time of the air. The results indicate that this technique enhances the internal air disturbance that affects convective heat transfer. The authors also assume that radiant heat losses can be reduced by using three upper panes which improve performance. Numerical and experimental studies of the tube-type solar air heater are performed by Afshari et al. [8] The effect of adding various turbulators was modeled using CFD approach, and the obtained numerical findings were used in the experimental device. The maximum instantaneous heater efficiency was ascertained to be $72.41 \%$. In the same context, Sözen et al. [9] studied the thermal performance improvement of tube-type indirect solar dryer with iron mesh modification. The results show that the use of mesh modification improved the thermal efficiency of the tube-type heater by about $11 \%$.

The same idea is the subject of considerable work done by Ebru and Fatih [10] who presented a study dealing with the analysis of the thermal performances of four types of a solar collector. The first is a simple solar collector and the three other solar collectors having different obstacle shapes. To reduce dead zones and to create turbulence, they also added small baffles of triangular, rectangular, and sheet types. It was found that the solar collector equipped with small obstacles reached the most important efficiency. It is also found that this configuration allows the reach of the highest output temperature.

Considerable work has been done by Zheng et al. [11] who has studied thermal performance as well as developed mathematical models of a new metal-corrugated air solar collector in the heating field in cold-climate buildings. This study has focused on the effects of the key structural and operating parameters and the analysis of the results obtained prove that they have a great influence on the thermal performance of the collector. In fact, the thermal efficiency of the collector increases with the increase of the settlement height, the specific surface area, the intensity of the radiation, the air velocity, and the ambient temperature, whereas it decreases with the increase of the width of the corrugated pad and the inlet air temperature. The thermal efficiency and the net exegetical efficiency of the sensor can reach $73 \%$. The improvement of the thermal performance of the solar collector with the increase of convective heat transfer can be effected by the deformation of the absorbent plate which has an artificial roughness that favors the increase of the exchange surface and the creation of turbulence. Among the rough surfaces that are treated in this perspective are $\mathrm{V}$ shaped rib roughness [12], Discrete W-shaped rib roughness [13], Multi V-shaped rib roughness [14], Arc shaped rib roughness [15], W-shaped rib roughness [16], and Transverse wire rib roughness [17]. These studies prove that the variation of relative roughness step affects the operating performance of the sensors, hence the need to identify the optimal values. With the development of tools and computer software, three-dimensional simulation through CFD software provides a solution to see some physical phenomena or calculate some parameters that are difficult to measure experimentally. By the using od a CFD program, Manjunath et al. [18] proposed a numerical simulation analysis of an air solar collector having a sinsoidal form absorber plate. This study was done in a range of the Reynolds numbers between 4000 and 24000 . The authors established that the presence of sinusoidal ripples increases the flow disturbances and significantly increases the heat transfer and as a result the average thermal efficiency is increased by about $12.5 \%$ compared to the ordinary air solar collector where the plate is smooth. Manjunath et al. [19] studied the influence of spherical obstacles on thermal efficiency and thermohydraulic performance on the solar collector. The analysis is carried out with a three-dimensional simulation with the CFD software where the turbulent model chosen is K-epsilon. The simulation shows that the thermal efficiency increases with the increase of the diameter of the sphere and the reduction of the relative roughness step. The thermal efficiency can reach up to $23.4 \%$ in percentage and the highest number of Nusselt is 2.5 times higher compared to the ordinary collector. The two numerical simulations done by the CFD software are in good agreement with the experimental results. This proves that this tool is potentially profitable for parametric studies of an air solar heater with a saving of time and without having costs like the experimental works. Various numerical and experimental studies presented in the literature show that the use of voluminous baffles inside the solar collector cavity makes it possible to optimize heat transfer conditions better than simple baffles that do not have large surfaces.

In this sense, we present a numerical study using the CFD software comparing the different volume shapes of the most famous baffles (spheres, cubes, cylinders, and pyramids) and identify the most efficient shapes. Our study aims to perform a special air solar collector configuration and design by developing a parametric optimization and investigation. The 
originality of our work is that we present a solar collector configuration with cubic obstacles integrated on the plate absorber of the solar collector. In this study, many angles of orientation are tested in order to enhance the thermal efficiency of the solar collector. The investigation is conducted by CFD numerical parametric study which intended to test the effect of the forms of baffles (Obstacles) on the heat transfer inside the air cavity. The study also deals with the effect of baffles and their orientation on the global thermal efficiency of the SFAC by creating turbulence zones and by minimizing the dead zones in order to avail of the absorbent surface inertia. The study was carried out for different relative roughness pitch b/a equal to 2,4 , and 6 for a turbulent regime in the range $2500 \leq \operatorname{Re} \leq 20000$.

\section{Mathematical Formulation: Dimensionless Numbers and Evaluation Parameters}

2.1. Dimensional Numbers. The dimensionless numbers that characterize a flow and are required for our study are mainly:

$$
\begin{aligned}
& \text { Reynolds number }: R_{e}=\frac{\rho V D_{h}}{\mu}, \\
& \text { Nusselt number }: N u=\frac{h D_{h}}{K},
\end{aligned}
$$

where $D_{h}$ presents the hydraulic diameter given by

$$
D_{h}=\frac{4 S}{P} .
$$

2.2. Thermal Efficiency. The thermal efficiency of SFAC is defined as the ratio of the actual thermal power exchanged and the theoretical maximum power:

$$
\eta_{\text {ther }}=\frac{Q_{u}}{Q_{\max }} \quad 0 \leq \eta \leq 1,
$$

where $Q_{u}=\dot{m} C_{p} \Delta T$ and $Q_{\max }=I . S$

2.3. Mechanical Pumping Power. The mechanical pumping power is defined as the force required for forcing the air to circulate inside the solar collector. This power noted Pm is given in the form:

$$
P_{m}=\dot{V} \Delta P
$$

2.4. Effective Efficiency. By using two expressions of thermal efficiency and mechanical power, we can write the mathematical expression of effective efficiency as follows as defined by Cortes and Piacentini [20] and Mittal and Varshney [21]:

$$
\eta_{e f f}=\frac{Q_{u}-\left(P_{m} / C\right)}{I . S},
$$

where the value of the constant $\mathrm{C}$ recommended by $[20,21]$ is 0.18 . This effective efficiency is used to evaluate the thermo-hydraulic performance of the solar collector.

\section{CFD Simulation}

The simulation was performed by using the CFD Fluent software. In this numerical program, various steps precede the launch of the simulation:

(i) The first step is to create the geometry to study. It is followed by the generation of a mesh that can be structured or unstructured in certain areas.

(ii) After the integration of the parameters and the input variables of the model, the software can solve the equations necessary for the simulation in every element of the considered mesh until the convergence.

(iii) When the convergence is obtained, the numerical model will be exploited for the evaluation of the Solar Flat Air Collector (SFAC) performances.

3.1. Description of the Solar Collector Configurations. The solar collector used for our study is a Solar Flat Air Collector (SFAC) that consists of an inlet section, an outlet section, and a cavity that contains an absorber containing baffles. This configuration is inspired by a publication by Manjunath et al. [19] illustrated in Figure 1, which presents a validation support for our study.

(i) The absorber situated at the top of the SFAC has a dimension of $1200 * 150 \mathrm{~mm}^{2}$ and a thickness equal to $0.5 \mathrm{~mm}$. It was conceived with aluminum material whose thermal-physical properties are as follows: density $2719 \mathrm{~kg} / \mathrm{m}^{3}$, specific heat $C p=871 \mathrm{~J} / \mathrm{kg} K$, and thermal conductivity $202.4 \mathrm{~W} / \mathrm{m} . \mathrm{K}$.

(ii) The SFAC is equipped with inlet and outlet air duct sections that are evaluated and selected on the basis of the ASHRAE 93-77 [22] standard for the turbulent regime.

(iii) On the SFAC absorber is fixed a series of baffles fabricated with aluminum materials and having a volume of $20 \mathrm{~mm}^{3}$ and having different shapes (Tables 1 and 2). The different SFAC configurations obtained by these management will be studied and compared on thermal basis in order to find the best configurations characterised by the highest performances.

(iv) The arrangements of these baffles inside the cavity and on the absorber plate are carried out in the following arrangement (Figure 2). The values of $a, b$, and $\mathrm{c}$ are summarized in Table 3 for all proposed arrangements.

3.2. Meshing Treatment. The developed FLUENT code is based on the discretization of the studied configuration by cutting it into structured or unstructured elementary volumes which will be taken as control volume (hexahedrons, tetrahedrons, and prisms) using the finite volumes method. In order to minimize the computation time and to keep the 


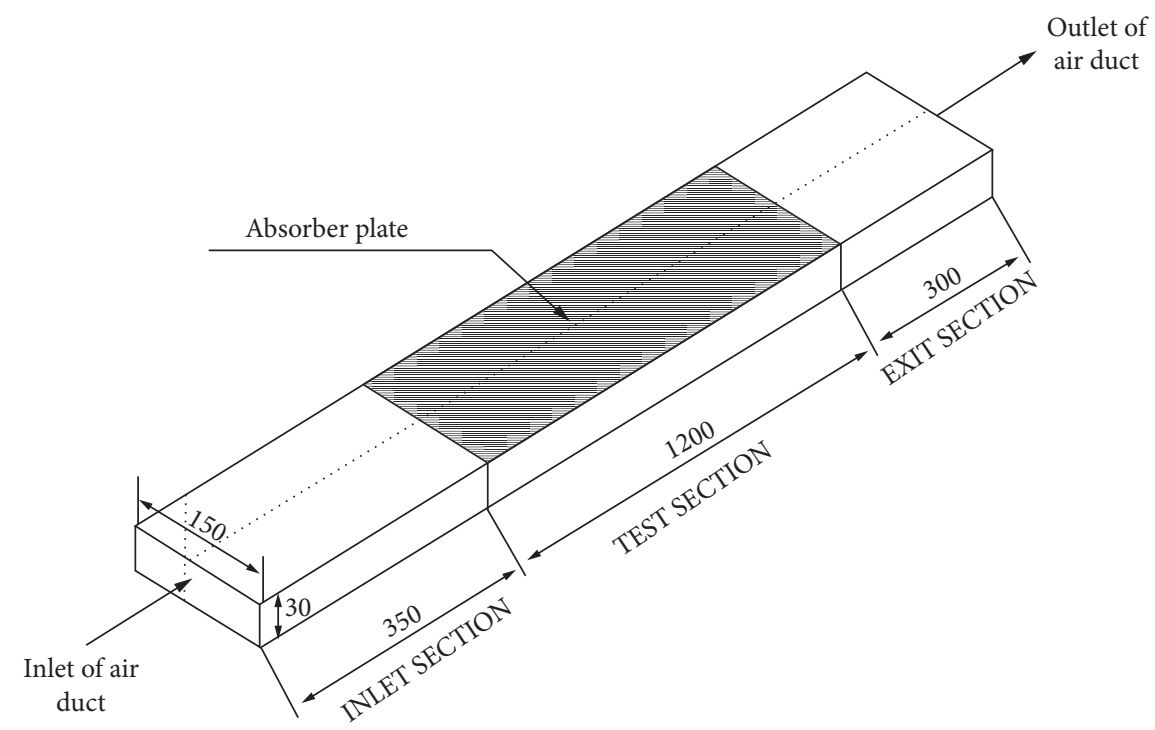

FIgURE 1: Dimensions of the solar collector studied [19].
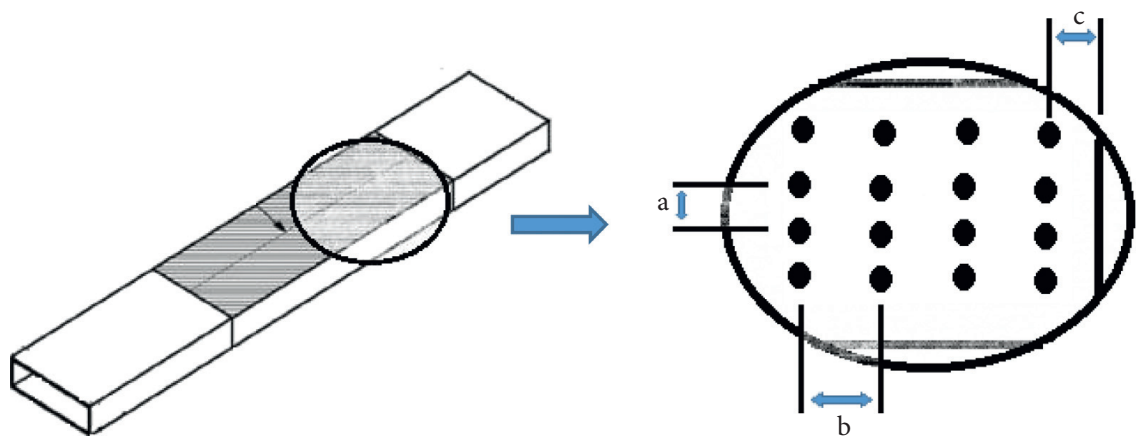

FIgURE 2: Baffles (Obstacles) arrangement on the absorbing plate of the SFAC.

TABle 1: Dimension of the baffels to be integrated inside the air cavity.

\begin{tabular}{lc}
\hline Form & Dimensions \\
\hline $\begin{array}{l}\text { Spheric } \\
\text { Cubic }\end{array}$ & Diameter $=20 \mathrm{~mm}$ \\
Cylinderical & Length of an edge $=20 \mathrm{~mm}$ \\
Pyramidal & Diameter of the base $=20 \mathrm{~mm} /$ Height $=20 \mathrm{~mm}$ \\
\hline
\end{tabular}

TABLE 2: Geometrical characteristics of the baffles.

\begin{tabular}{lccc}
\hline $\begin{array}{l}\text { Geometric } \\
\text { shape of the } \\
\text { obstacle }\end{array}$ & $\begin{array}{c}\text { Total obstacle } \\
\text { area }\end{array}$ & $\begin{array}{c}\text { Geometric } \\
\text { shape of the } \\
\text { attack face } \\
\text { exposed directly } \\
\text { to the air flow }\end{array}$ & $\begin{array}{c}\text { Surface of the } \\
\text { leading face } \\
\text { exposed directly } \\
\text { to the air flow }\end{array}$ \\
\hline $\begin{array}{l}\text { Spherical } \\
\text { Cubic }\end{array}$ & $\begin{array}{c}1256.64^{2} \mathrm{~mm} \\
2400^{2} \mathrm{~mm}\end{array}$ & $\begin{array}{c}1 / 2 \text { of a sphere } \\
\text { A square }\end{array}$ & $\begin{array}{c}628.32^{2} \mathrm{~mm} \\
400^{2} \mathrm{~mm}\end{array}$ \\
Cylindrical & $1884.95^{2} \mathrm{~mm}$ & $\begin{array}{c}1 / 2 \text { of the lateral } \\
\text { surface }\end{array}$ & $314.2^{2} \mathrm{~mm}$ \\
Pyramidal & $1458.3^{2} \mathrm{~mm}$ & A triangle & $264.57^{2} \mathrm{~mm}$ \\
\hline
\end{tabular}

precision of the meshes, which have an importance in the quality of the results, the following approaches were taken:

(i) The use of symmetry along the solar collector for certain symmetrical configurations.

(ii) The simplification of the solar collector geometry by eliminating irrelevant structures for the simulation. We mainly consider two sections of air entry and air exit.

(iii) The choice of the most suitable mesh which will enhance the quality of the results and reduce the time of computation by conducting mesh independence (Figure 3). Figure 3 and Table 4 illustrate this test for the solar collector with the simple absorbent plate with different Reynolds numbers $\left(\mathrm{Re}_{1}=5000, \mathrm{Re}_{2}=7500, \mathrm{Re}_{3}=10000, \mathrm{Re}_{4}=12500\right.$, $\mathrm{Re}_{5}=15000$, and $\left.\mathrm{Re}_{6}=20000\right)$ and each time the $\Delta T$ (difference between inlet and outlet temperature) is calculated for each mesh. 
TABle 3: Dimension of the chosen geometry.

\begin{tabular}{lccccc}
\hline Configuration & Value of a & Value of b & Value of c & Number of obstacles/line & Number of obstacles/column \\
\hline $\mathbf{b} / \mathbf{a}=\mathbf{2}$ & $37.5 \mathrm{~mm}$ & $75 \mathrm{~mm}$ & $37.5 \mathrm{~mm}$ & 16 & 4 \\
$\mathbf{b} / \mathbf{a}=\mathbf{4}$ & $37.5 \mathrm{~mm}$ & $150 \mathrm{~mm}$ & $75 \mathrm{~mm}$ & 8 & 4 \\
$\mathbf{b} / \mathbf{a}=\mathbf{6}$ & $37.5 \mathrm{~mm}$ & $225 \mathrm{~mm}$ & $37.5 \mathrm{~mm}$ & 6 & 4 \\
\hline
\end{tabular}

TABLE 4: Characteristics of the tested meshes.

\begin{tabular}{lcc}
\hline \multirow{2}{*}{ Mesh number } & \multicolumn{2}{c}{ Characteristics } \\
& Number of meshes & Number of nodes \\
\hline 1 & 61677 & 72896 \\
2 & 91200 & 105651 \\
3 & 132741 & 151360 \\
$\mathbf{4}$ & $\mathbf{2 0 0 0 0 0}$ & $\mathbf{2 2 4} \mathbf{9 6 1}$ \\
5 & 345600 & 381433 \\
6 & 402001 & 432784 \\
\hline
\end{tabular}

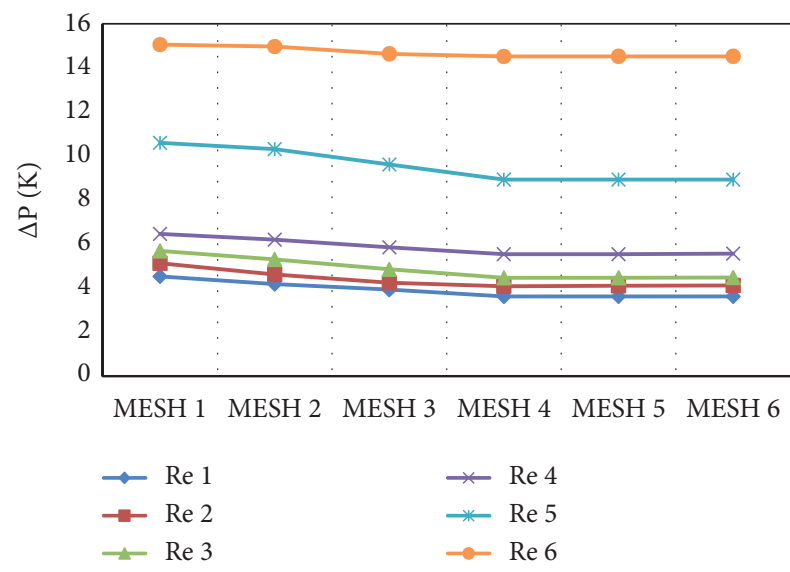

Figure 3: Mesh independence test.

Figure 4 illustrates the meshes of the calculation domain used for solar collectors without (a) and with cubic baffles (b).

\subsection{Choice of Physical Models}

3.3.1. Turbulence Model Choice for Simulation. For the resolution of the RANS (Navier-Stokes equations obtained by passing to the Average Reynolds), we have in Fluent several classes of turbulence models, which are equations that complete the balance equations and allow the closure of the system [23-25]. Considering the geometry and the flow conditions, we have chosen the models $k-\varepsilon$ which is judged by several authors who prove that the latter is better adapted to the physical problems of flows and gives better flow conservation $[26,27]$.

3.3.2. The Equations Needed for the Simulation. The necessary equations for the flow simulation are classical NAVIER-STOKES mass and momentum conservation equations, which are written as follows for an incompressible fluid:

(i) Equation of continuity

$$
\frac{\partial u}{\partial x}+\frac{\partial v}{\partial y}+\frac{\partial w}{\partial z}=0
$$

(ii) Momentum equation

$$
\frac{\partial \rho \vec{V}}{\partial t}+\vec{\nabla} \cdot(\rho \vec{V} i \vec{V} i)=\rho \vec{f}-\vec{\nabla} \cdot P-\vec{\nabla} \tau .
$$

(iii) Energy conservation equation

$$
\frac{\partial u}{\partial t}+u \frac{\partial u}{\partial x}+v \frac{\partial u}{\partial y}+w \frac{\partial u}{\partial z}=\frac{K}{\rho C_{p}}\left(\frac{\partial^{2} T}{\partial x^{2}}+\frac{\partial^{2} T}{\partial y^{2}}+\frac{\partial^{2} T}{\partial z^{2}}\right) .
$$

(iv) Transport equations

The introduction of transport equations makes it possible to follow the evolution of certain characteristic variables of turbulence. Their expressions given below were obtained after manipulation of averaged and nonaveraged Navier-Stokes equations [23]:

One related to turbulent kinetic energy $k$ :

$$
\begin{aligned}
\rho\left(\frac{\partial k}{\partial t}+\frac{\partial}{\partial x_{i}}\left(k V_{i}\right)\right)= & \frac{\partial}{\partial x_{j}}\left[\left(\mu+\frac{\mu t}{\sigma k}\right) \frac{\partial k}{\partial x_{j}}\right] \\
& +P_{k}+P_{b}-\rho \varepsilon+S_{k} .
\end{aligned}
$$

And, the other one about the rate of kinetic energy dissipation $\varepsilon$ :

For the model, we chose $k-\varepsilon$ Realizable:

$$
\begin{aligned}
\rho\left(\frac{\partial \varepsilon}{\partial t}+\frac{\partial}{\partial x_{i}}\left(\varepsilon V_{i}\right)\right)= & \frac{\partial}{\partial x_{j}}\left[\left(\mu+\frac{\mu t}{\sigma \varepsilon}\right) \frac{\partial \varepsilon}{\partial x_{j}}\right] \\
& +\rho C_{\varepsilon 1} S_{\varepsilon}-C_{\varepsilon 2} \rho \frac{\varepsilon^{2}}{k+\sqrt{V \varepsilon}}+C_{\varepsilon 1} \frac{\varepsilon}{k} C_{\varepsilon 3} P_{b}+S_{\varepsilon} .
\end{aligned}
$$

3.3.3. Properties of the Air Inside the Solar Collector Cavity. The thermo-physical properties of air vary with pressure, temperature, and humidity. For the accuracy of the results obtained from the simulation, we will integrate the following thermo-physical properties in the selected turbulence model that are valid for a the temperature ranges between 280 and $470 \mathrm{~K}[22,23-30]$ :

$$
\rho=3.9147-0.016082 T+2.9013 \times 10^{-5} T^{2}-1.9407 \times 10^{-5} T^{3},
$$

$$
\mu=\left(1.6157+0.06523 T-3.0297 \times 10^{-5} T^{2}\right) 10^{-6},
$$




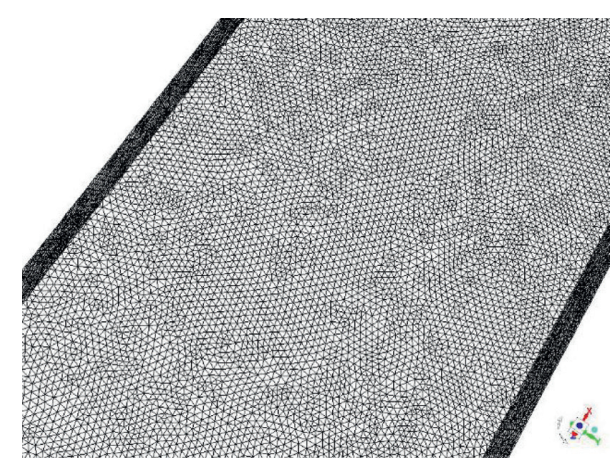

(a)

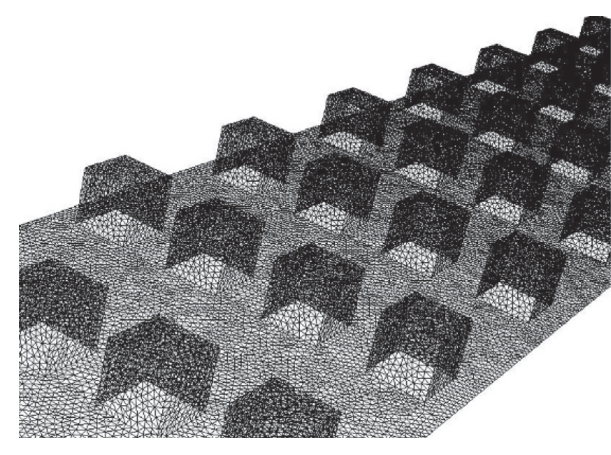

(b)

FIGURE 4: Mesh configurations of solar collector without and with cubic baffles.

$$
K=\left(0.0015215+0.097459 T-3.3322 \times 10^{-5} T^{2}\right) 10^{-3},
$$

$$
\begin{aligned}
C_{p}= & 1009.26-0.0040403 T+0.00061759 T^{2} \\
& -0.0000004097 T^{3} .
\end{aligned}
$$

3.3.4. Boundary Conditions. The boundary conditions chosen for the computer model are as follows:

(i) At the inlet of the cavity is maintained an initial air velocity that corresponds to a Reynolds number between 2500 and 20000 with a temperature equal to $307 \mathrm{~K}$.

(ii) At the outlet of the channel, applied pressure is equal to $101325 \mathrm{~Pa}$.

(iii) The solar collector is considered as an isolated and an adiabatic cavity.

(iv) The solar radiation flux applied on the solar collector surface and on its components is equal to $1084 \mathrm{~W} / \mathrm{m}^{3}$.

\subsubsection{Parameters of the Solver and the Simulation Convergence.}

(i) For our simulation, the solver is based on double precision pressure as well as a SIMPLE algorithm for coupling pressure and velocity.

(ii) The choice of a Second-Order discretization scheme leads to a rapid pressure convergence compared to other schemes.

(iii) The convergence of the iterative process is determined by the residue concept. Discretized equations are considered to converge when the curves become stable and relatively flat: less than $10^{-6}$ for energy and less than $10^{-5}$ for momentum and continuity equations.

\section{Results and Discussions}

4.1. Validation of Numerical Results. The validation of the numerical model is an essential step to test the reliability of the studied software and its capacity to produce accurate results despite calculation errors. To validate the results of the simulations carried out in our model, we have chosen two curves showing the results of a publication by Bhagoria et al. [22]. The study proposed by Manjunath et al. deals with the effect of spherical baffles turbulence generators on thermal efficiency and thermo-hydraulic performances of an air-flat plate solar collector for the Reynolds number range of $410^{3}-2510^{3}$. The investigation presented by Manjunath et al. concerned various sphere diameters (D) $(5,10,15,20$, and $25 \mathrm{~mm})$ and different roughness pitches (P/D) $(3,6$, and 12). The numerical results presented by Manjunath et al. are validated against experimental results and are found to have good agreement. Accordingly, we have exploited this investigation to validate our CFD simulation program.

The comparison of the variation of the Nusselt number and thermal efficiency versus the Reynolds number between the referent numerical study and our digital study is illustrated in Figures 5 and 6 , respectively. The obtained results and the results given by Manjunath et al. through the two curves followed the same trends and present very similar values. However, a little difference between the two studies is noted. It is found that the thermal efficiency for Reynold's superior to 17103 and Reynold's inferior to 7103 ranges, respectively, between 17 and 14\%. It was found that the two CFD models are very close. The mismatch between the two results can be explained by the specific conditions of the CFD program proposed by Manjunath et al., compared to our numerical program. However, we can globally consider that our model with the imposed limiting conditions can reproduce the results proposed by Manjunath et al. Consequently, we can exploit our developed model in the investigation of the different arrangements and configurations in order to obtain the most appropriate and feasible Solar Flat Air Collector (SFAC).

4.2. Effects of Obstacle Geometries on Flow. In order to characterize the different SFAC configurations, we calculated the Nusselt number for each type of solar collector configurations with different geometries of baffles (obstacles) for three roughness steps by varying each time the Reynolds number. The characterization is based on the most 


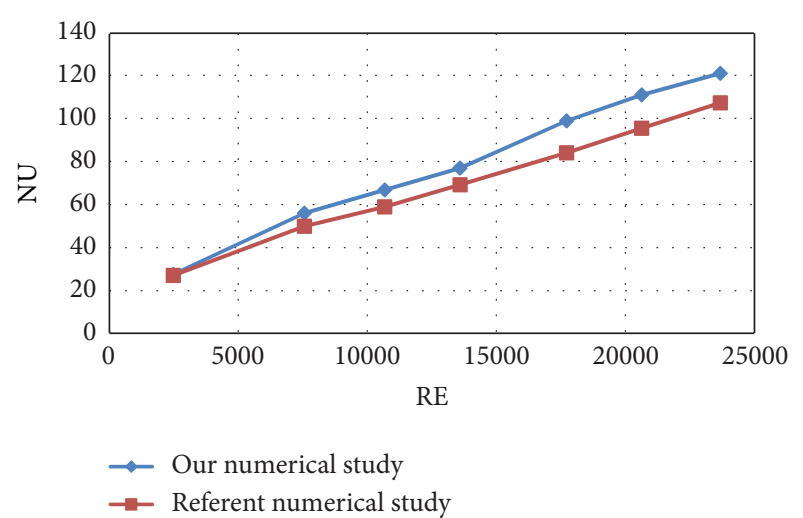

Figure 5: Comparison of the Nusselt number versus the Reynolds number for our study and reference study.

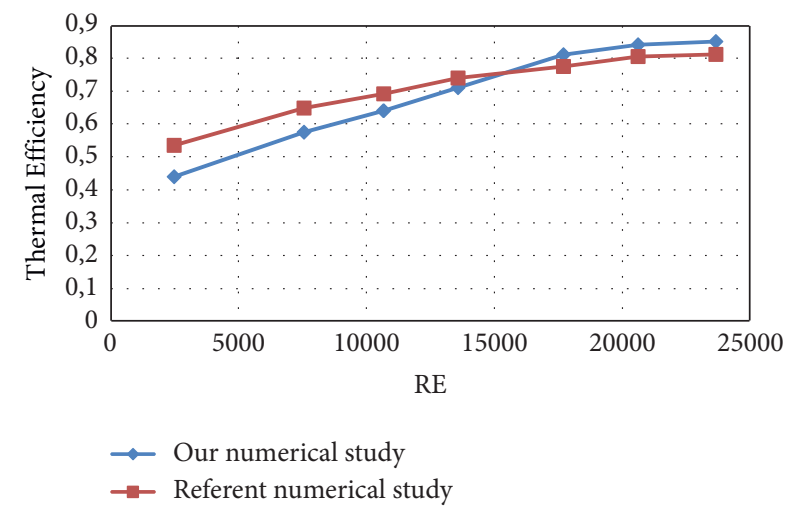

FIgure 6: Comparison of thermal efficiency versus the Reynolds number function for our study and reference study.

adapted configuration that can create more turbulence inside the SFAC air cavity. The results are represented in Figures $7(\mathrm{a})-7(\mathrm{c})$. It was found that the lowest Nusselt values are attained for the ordinary configuration (without obstacles). Besides, it was found that the Nusselt number increases with the Reynolds number for the different configurations. It was seen that the spherical shape with a relative roughness pitch of $\mathrm{b} / \mathrm{a}=2$ has the highest Nusselt number which can exceed 120 . We also noted that the results obtained with the use of the cubic form are close to those found for spherical obstacles. It is important to assert that, for the same configuration, the same relative roughness pitch and for the same Reynolds number, the present study offers a good enhancement of the Nusselt number compared with results published in a previous paper [31].

To highlight the SFAC with a cubic obstacles configuration, a numerical simulation was proposed. It investigates the effect of the cubic obstacles on the air flow inside the SFAC air cavity. In Figures 8 and 9 are represented the evolution of the air-flow velocity inside the SFAC cavity without (Figure 8) and with cubic obstacles (Figure 9) (Relative roughness pitch $\mathrm{b} / \mathrm{a}=2$ ) for a chosen Reynolds number equal to 15000 . It was found that for an ordinary configuration (without obstacles), the air flow is almost uniform inside the cavity and the velocity becomes slower towards the ends. The results also showed that inside a cavity containing cubic obstacles, we can observe the creation of turbulence in the vicinity of the obstacles which makes the medium homogeneous and cancels the dead zones inside the air cavity of the solar collector.

4.3. Effects of Relative Roughness Pitch (b/a) on the Cubic Obstacles SFAC Configuration Performances. In Figure 10 is represented the variation of the Nusselt numbers as a function of the Reynolds number without and with cubic baffles for different pitch; $b / a=2 ; b / a=4$; and $b / a=6$. It is found that the Nusselt number increases as a function of the Reynolds number. Indeed, the Nusselt number reaches a value close to 120 for a Reynolds number equal to $2310^{3}$ and a relative roughness pitch $b / a=2$. In Figure 11 is represented the influence of the relative roughness pitch (b/a) of the cubic obstacle on the turbulent intensity distribution and on the air flow inside the SFAC air cavity. It was found that the turbulence varies remarkably depending on the position inside the solar collector cavity. It becomes intense in the vicinity of obstacles. It was also clear that this turbulence increases by reducing the relative roughness pitch. It was found that for a relative roughness pitch $\mathrm{b} / \mathrm{a}=2$, the SFAC reaches the most appropriate turbulence intensity rate. The performance of our solar collector with its four configurations was also evaluated by considering other parameters such as the thermal efficiency, the pressure drop, the mechanical pumping power, and the effective efficiency, which are studied according to the Reynolds number changes.

In Figure 12 is represented the variation of the thermal efficiency of the solar collector as a function of the Reynolds number. Figure 12 shows the variation of the thermal efficiency of solar collector with a smooth absorber and with cubic obstacles having different relative roughness pitches. It was noted that the thermal efficiency which characterizes the performance of our solar collector varies in an increasing way for the four solar collector configurations. It was also seen that the evolution of thermal efficiency depends on the roughness step. The highest values are recorded for the solar collector with a roughness pitch $\mathrm{b} / \mathrm{a}=2$ which can reach a maximum of about $80 \%$ for a Reynolds value equal to $2310^{3}$.

In Figure 13 is represented the Reynolds impact on the pressure drop for the different SFAC configurations. It was showed that during the air-flow circulation, the initial pressure increases with the Reynolds number increasing. We also found that this pressure drop increases by decreasing the space between the cubic obstacles. The results is explained by the fact the volume of the obstacles integrated inside the air cavity reduces the airflow inside the air cavity. In Figure 14 is represented the variation of the mechanical pumping power of the solar collector for different configurations. It was seen that the mechanical pumping powers of the different configurations according to the Reynolds number have the same tendency of the pressure drop variation. Due to the strong increase in pressure drop between the inlet section and the air outlet section, the model reacts in a way that ensures flow invariability from where constant air circulation is kept in the air cavity of the SFAC. It was also 


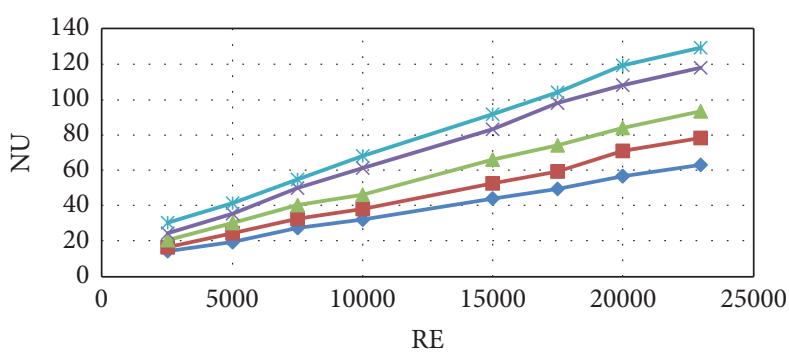

$\rightarrow$ Ordinary solar collector

$\simeq$ Solar collector with cylindrical baffles

* Solar collector with spherical baffles

$\rightarrow$ Solar collector with pyramidal baffles

* Solar collector with cubic baffles

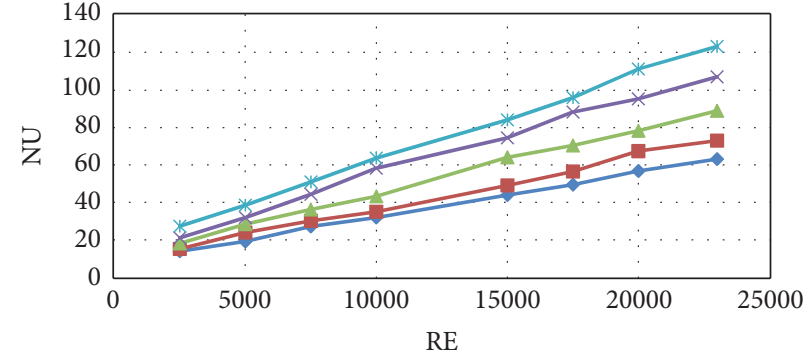

$\rightarrow$ Ordinary solar collector

$\leftarrow$ Solar collector with cylindrical baffles

* Solar collector with spherical baffles

$\rightarrow$ Solar collector with pyramidal baffles

* Solar collector with cubic baffles

(b)

(a)

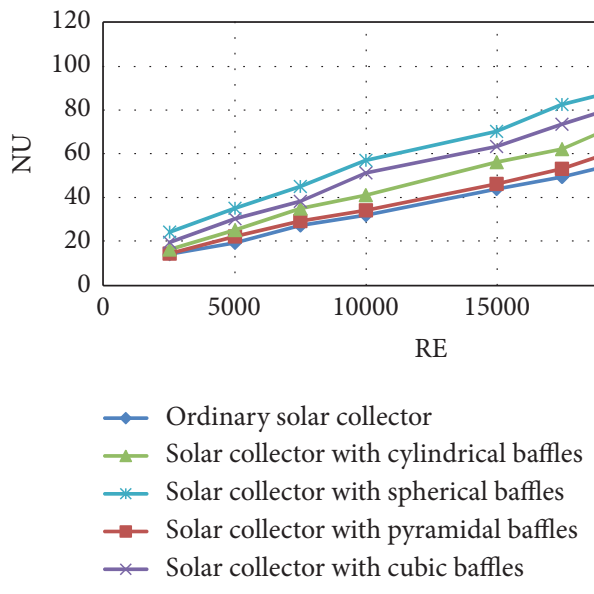

(c)

Figure 7: Nusselt number vs. Reynolds according to presented configurations and relative roughness pitches: $(\mathrm{a}) \mathrm{b} / \mathrm{a}=2$, $(\mathrm{b}) \mathrm{b} / \mathrm{a}=4$, and (c) $\mathrm{b} / \mathrm{a}=6$.

Velocity magnitude $(\mathrm{m} / \mathrm{s})$

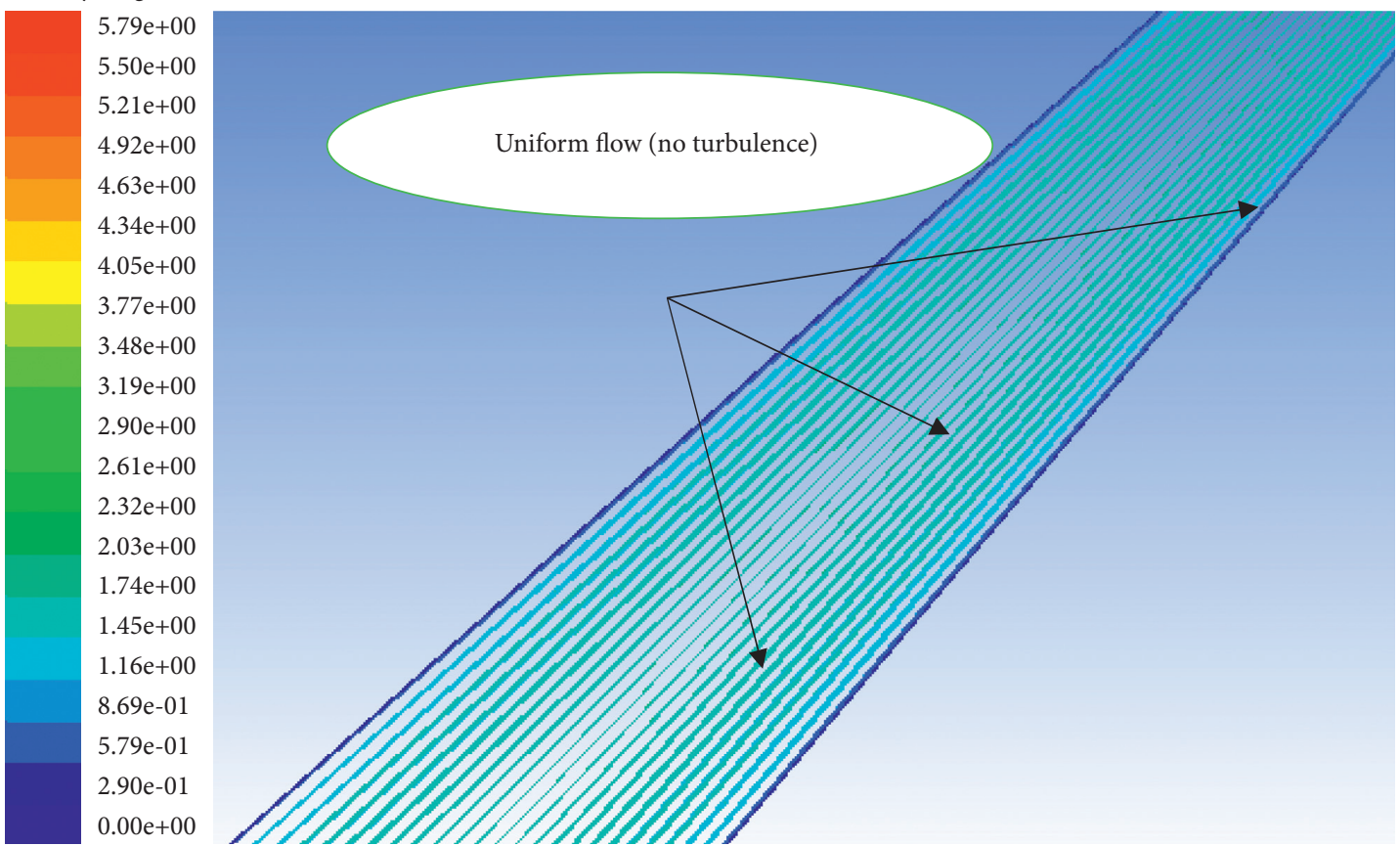

FIgURE 8: Airflow trajectory curves (colored by velocity magnitude in $\mathrm{m} / \mathrm{s}$ ) for a plate without obstacles of cubic shape. 
Velocity magnitude $(\mathrm{m} / \mathrm{s})$

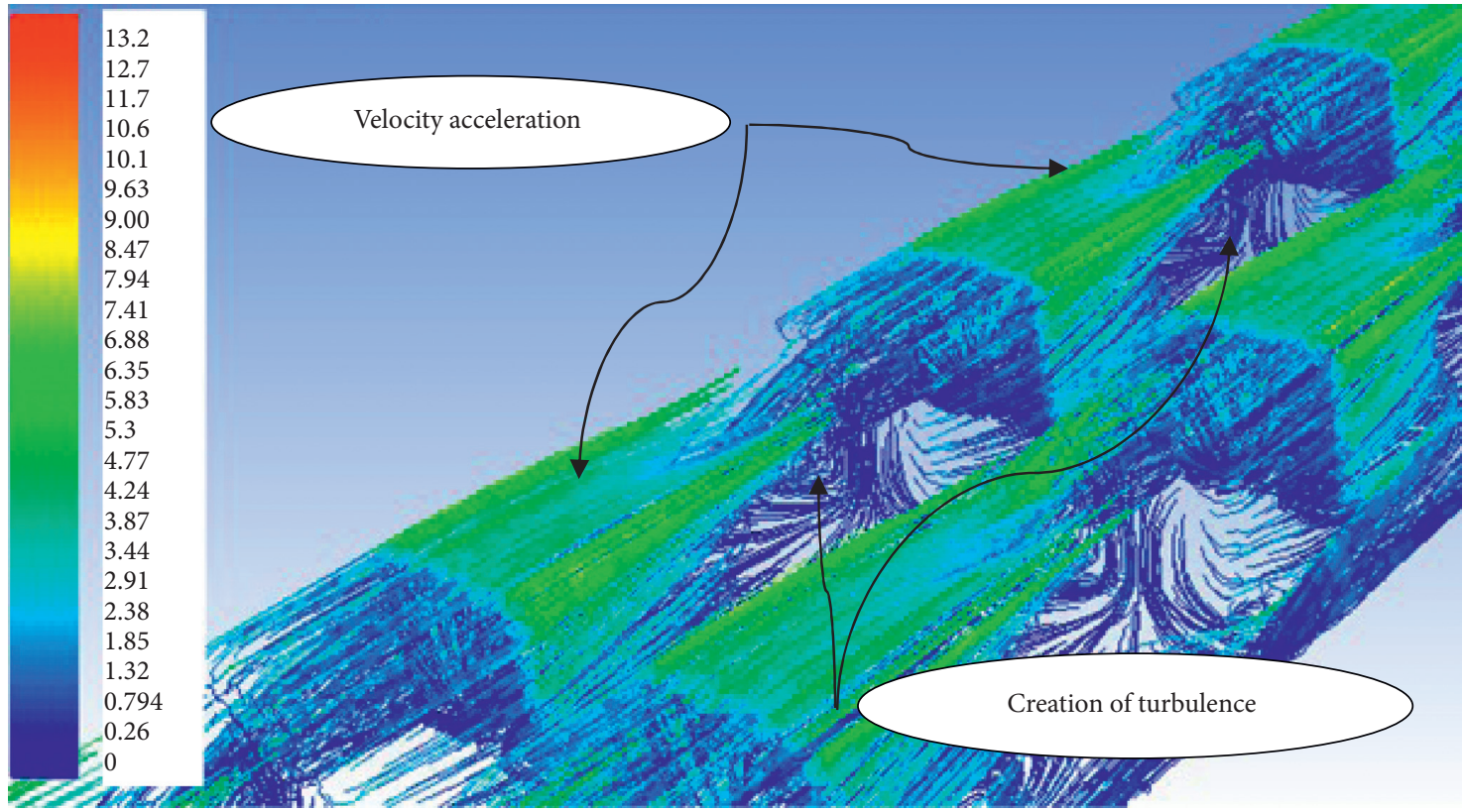

FIgURE 9: Air-flow trajectory curves (colored by velocity magnitude in $\mathrm{m} / \mathrm{s}$ ) for a plate with cubic shape obstacles.

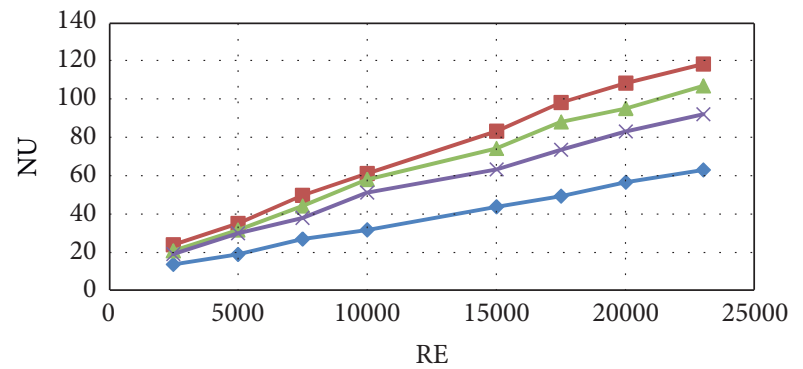

$\rightarrow$ Ordinary solar collector
$\rightarrow$ Relative roughness pitch $: \mathrm{b} / \mathrm{a}=2$
$\multimap$ Relative roughness pitch $: \mathrm{b} / \mathrm{a}=4$
$\leftarrow$ Relative roughness pitch $: \mathrm{b} / \mathrm{a}=6$

FIGURE 10: Nusselt number vs Reynolds without and with cubic obstacles for three relative roughness pitch b/a.

seen that the air pumping force increases by the decreasing of the distance between the cubic obstacles.

In Figure 15 is illustrated the values of the effective efficiency obtained during the simulation by varying each time the Reynolds number for the four model configurations. It is noted that the effective efficiency which characterizes the performance of the solar collector and its capacity to achieve its ends increases considerably as a function of Reynolds number up to a value of 17500 with the favoring of the configuration with the relative roughness pitch of $b / a=2$, which can reach $70 \%$. The second configuration considered effective is that of relative roughness pitch $\mathrm{b} / \mathrm{a}=4$ as long as the third efficient model is reserved for the largest roughness pitch. The least efficient configuration is that of a solar collector with the smooth absorbent plate. Beyond Reynolds value of 17500 , the values of the effective efficiency undergo a decrease. Consequently, the most appropriate conditions to have an optimal thermal efficacy (about 70\%) is to assure an air pumping with a Re number equal to 17500 and with a relative roughness pitch $\mathrm{b} / \mathrm{a}=2$.

4.4. Area Attack Orientation Effects on Flow and on Thermal Performances of the SFAC. Considering the promising results of the use of the cubic form as baffle obstacles for the performance improvement of the SFAC, another set of simulations were conducted. The numerical investigation was directed towards the study of the effect of the cube angle orientation on the thermal performances of the SFAC and to compare with spherical obstacles in order to show that the change of the orientation improves the cubic configuration. In this context, three orientations are proposed (Table 5):

In Figures 16(a)-16(c) is represented the variation of the Nusselt number for the spherical and the cubic configurations as a function of Reynolds for a relative roughness pitches: $\mathrm{b} / \mathrm{a}=2,4$, and 6 , respectively. The simulation shows that with an orientation of $45^{\circ}$ we can reach a total attack surface equal to $800 \mathrm{~mm}^{2}$ since the attack is made on two surfaces of $400 \mathrm{~mm}^{2}$ each. It is shown that the Nusselt numbers increase with the increase of the Reynolds number and sense its low values for a Reynolds number equal to 2500. By analyzing these curves, we can notice that the Nusselt value for the configuration which contains cubes with an orientation of $45^{\circ}$ with a roughness pitch $b / a=2$ is greater compared to the other configurations studied, even those that contain spheres. For a Reynolds number value of 23000 and for a configuration which combines the orientation of $45^{\circ}$ and the relative roughness pitch of $b / a=2$, the 
Turbulent intensity distribution (\%)

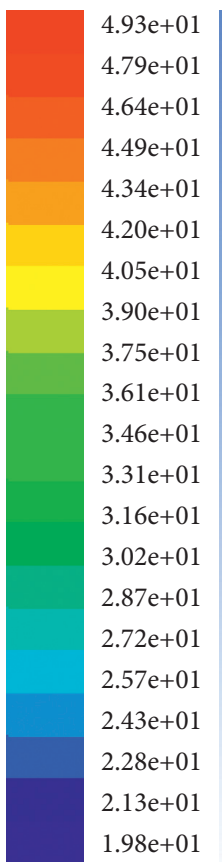

bulent intensity distribution (\%)

\begin{tabular}{l}
$2.35 \mathrm{e}+02$ \\
$2.24 \mathrm{e}+02$ \\
$2.13 \mathrm{e}+02$ \\
$2.02 \mathrm{e}+02$ \\
$1.91 \mathrm{e}+02$ \\
$1.79 \mathrm{e}+02$ \\
$1.68 \mathrm{e}+02$ \\
$1.57 \mathrm{e}+02$ \\
$1.46 \mathrm{e}+02$ \\
$1.35 \mathrm{e}+02$ \\
$1.23 \mathrm{e}+02$ \\
$1.12 \mathrm{e}+02$ \\
$1.01 \mathrm{e}+02$ \\
$9.00 \mathrm{e}+01$ \\
$7.88 \mathrm{e}+01$ \\
$6.76 \mathrm{e}+01$ \\
$5.65 \mathrm{e}+01$ \\
$4.53 \mathrm{e}+01$ \\
$3.41 \mathrm{e}+01$ \\
$2.29 \mathrm{e}+01$ \\
$1.18 \mathrm{e}+01$ \\
\hline
\end{tabular}

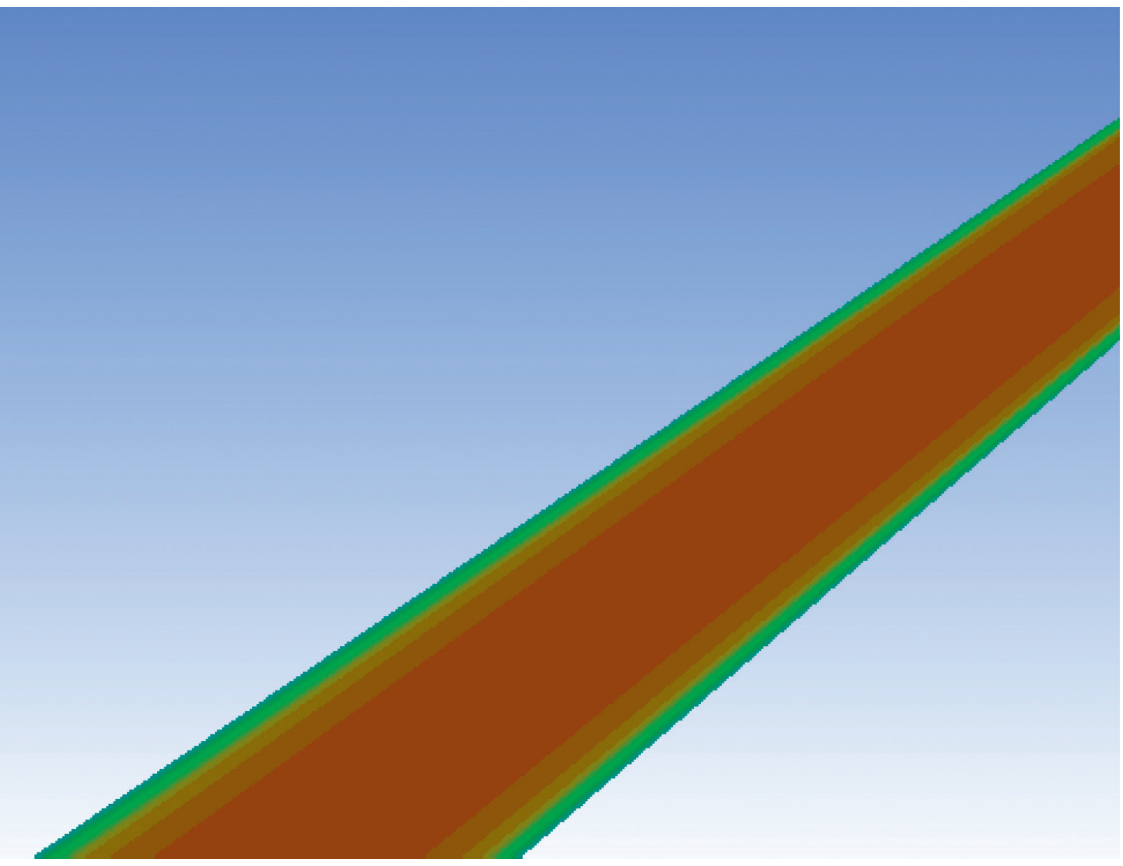

(a)

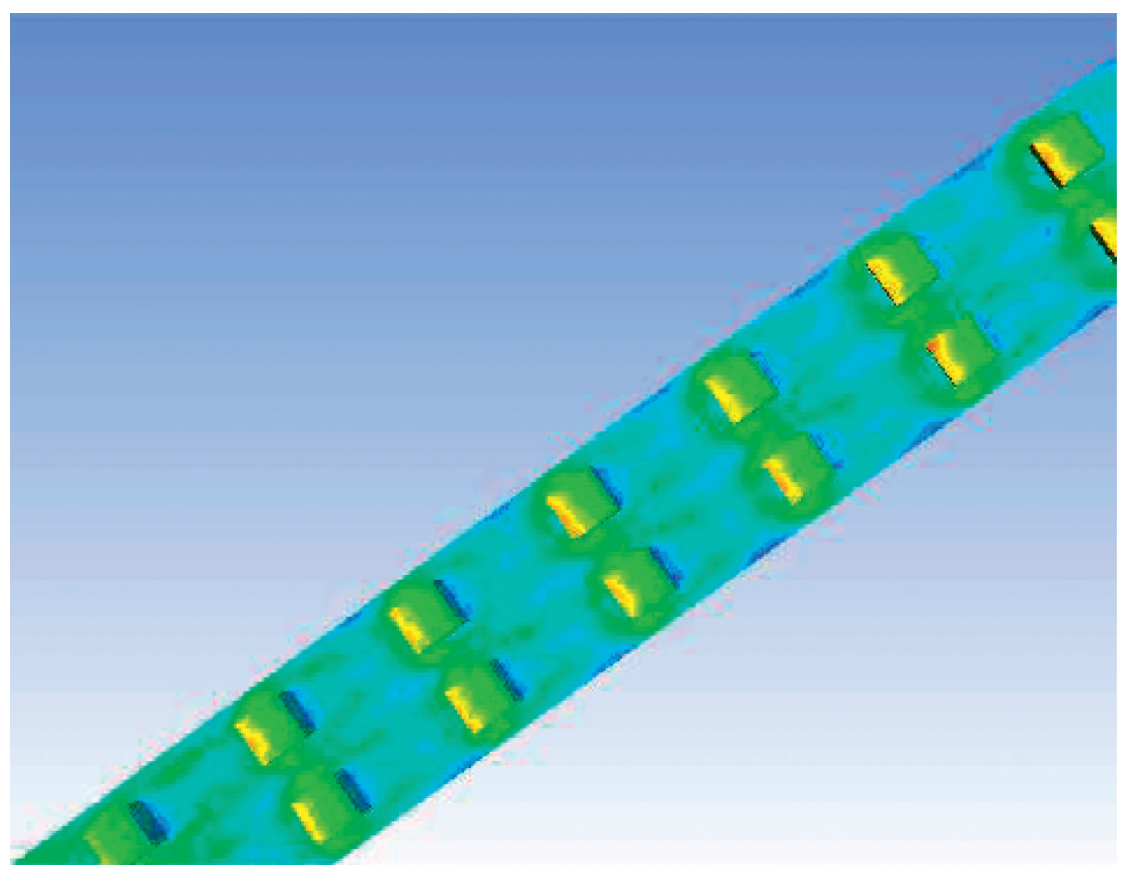

(b)

Figure 11: Continued. 
Turbulent intensity

distribution (\%)
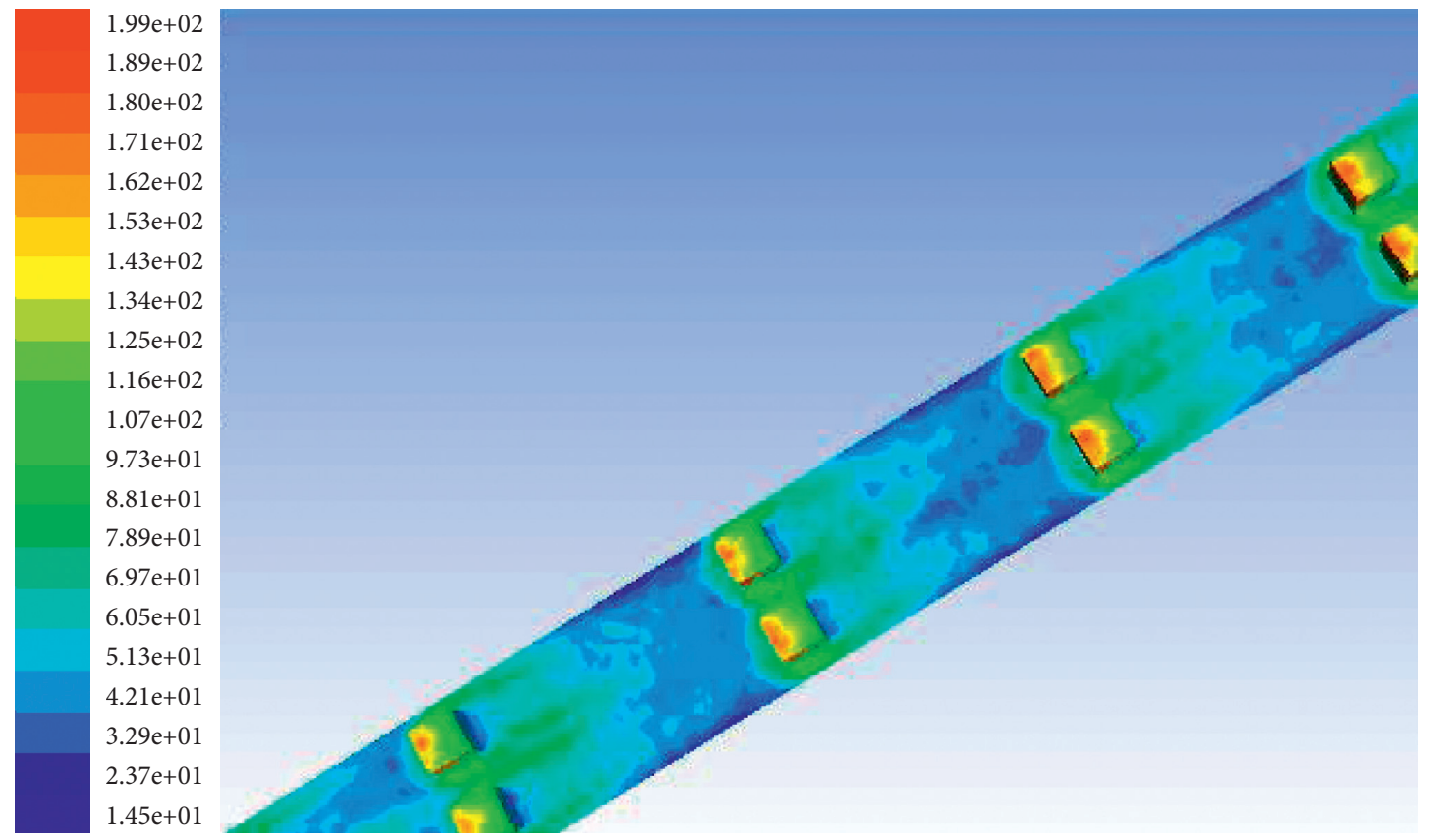

(c)

Turbulent intensity

distribution (\%)

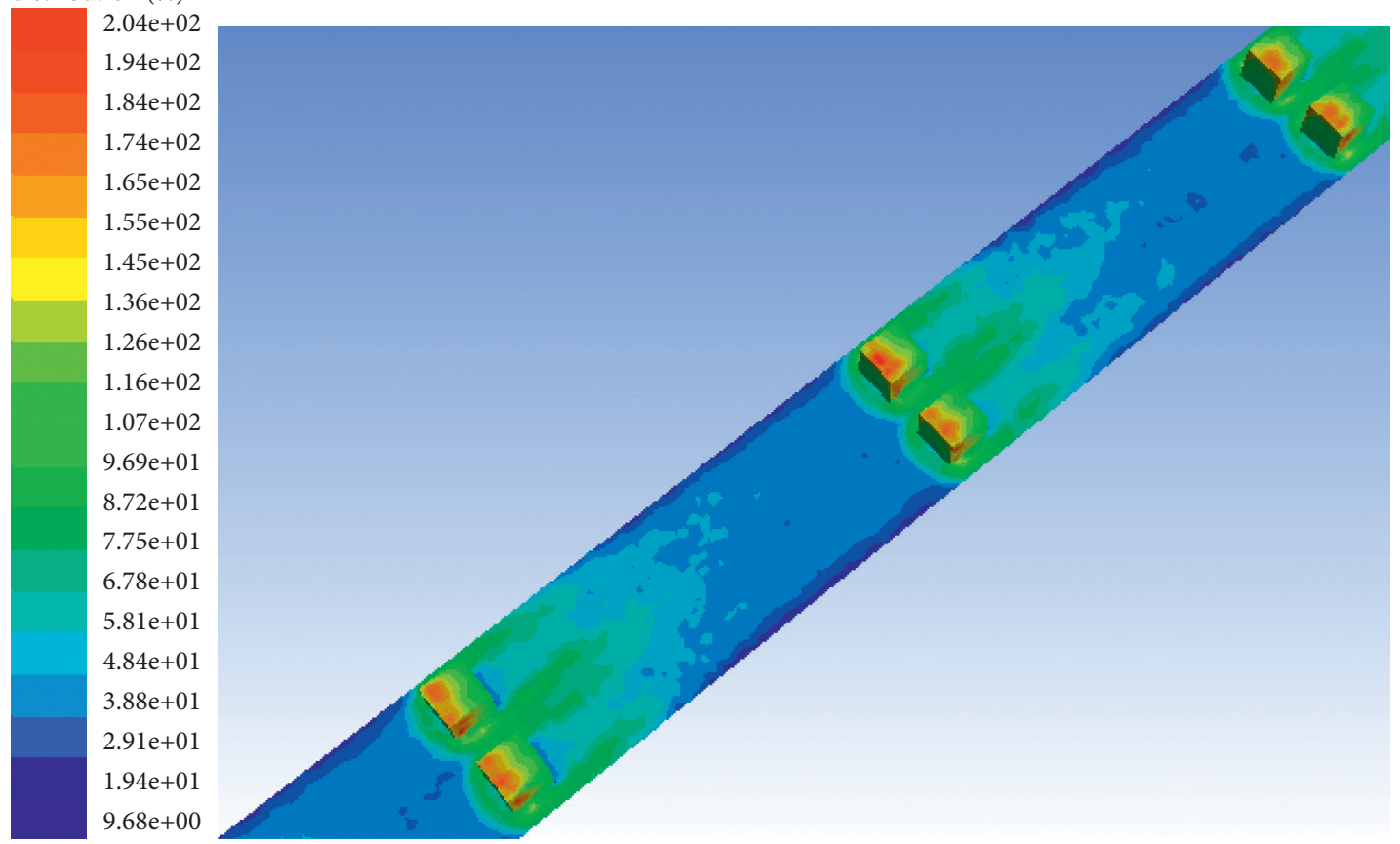

(d)

FIGURE 11: Influence of relative roughness pitch (b/a) of the cubic obstacle on the turbulent intensity distribution (\%) and on the air flow inside the SFAC air cavity. (a) Without cubic baffles inside the cavity, (b) relative roughness pitch: b/a = 2, (c) relative roughness pitch: b/ $\mathrm{a}=4$, and (d) relative roughness pitch: $\mathrm{b} / \mathrm{a}=6$.

Nusselt number reaches a large value which exceeds $7 \%$ of the value of Nusselt for the configuration which contains spherical baffles and $55.46 \%$ higher than a configuration which contains a smooth plate.
To highlight the effect of the cubic obstacle angle orientation, we presented in Figure 17 the variation of the Nusselt number for the three angles of orientation $0^{\circ}, 22.5^{\circ}$, and $45^{\circ}$ for a relative roughness pitch equal to $\mathrm{b} / \mathrm{a}=2$ and 


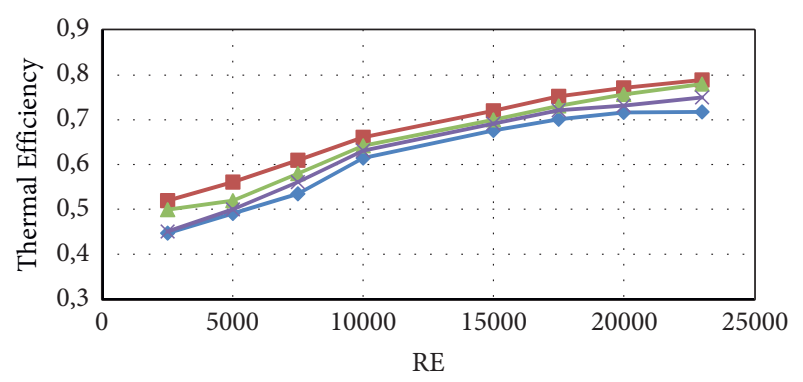

$\rightarrow$ Ordinary solar collector
$\rightarrow$ Relative roughness pitch $: \mathrm{b} / \mathrm{a}=2$
$\leftarrow$ Relative roughness pitch $: \mathrm{b} / \mathrm{a}=4$
$\leftarrow$ Relative roughness pitch $: \mathrm{b} / \mathrm{a}=6$

FIgURE 12: Solar collector thermal efficiency as a function of the Reynolds number.
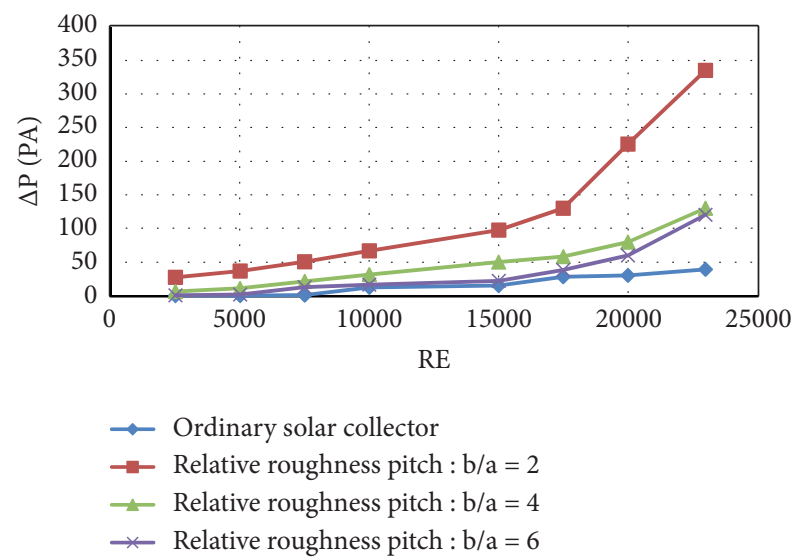

Figure 13: Pressure drop as a function of the Reynolds number.

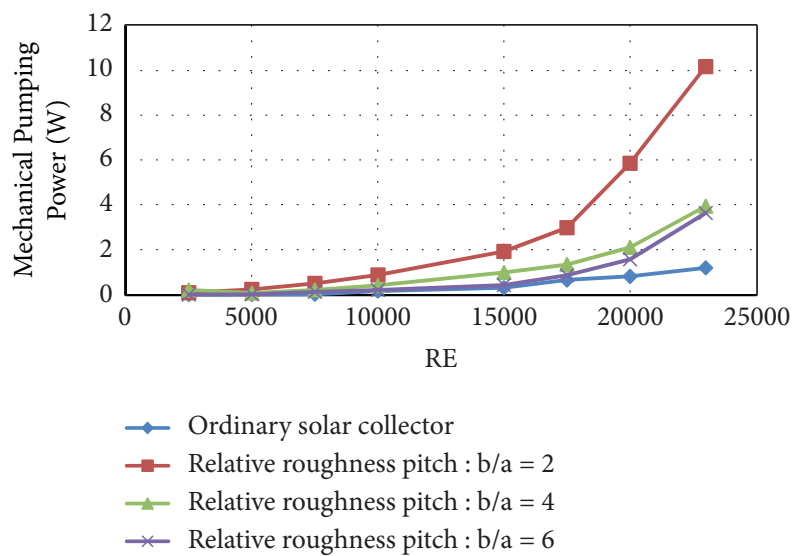

FIGURE 14: Mechanical pumping power vs the Reynolds number.

a flow rate that corresponds to the Reynolds number equal to 23000. It is noted that the values of the Nusselt number are very important in the vicinity of the baffles. Besides, the configuration where the angle of orientation is equal to $45^{\circ}$ presents values of the Nusselt number higher than the other

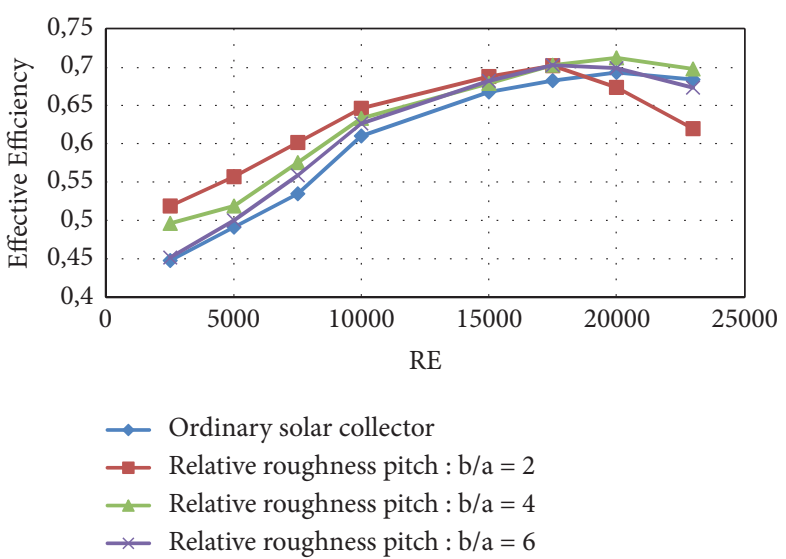

Figure 15: Variation in effective efficiency with the Reynolds number.

configurations. The promising performance of the cubic shape with an orientation of $45^{\circ}$ is also visible on the curves below (Figures 18-20 ) which describe the evolution of thermal efficiency as a function of the Reynolds number for the three studied relative roughness pitches. Figures 18-20 show that the thermal efficiency of the sensor is sensitive by the cube orientation angle as well as the roughness pitch. The results of the simulations show that the thermal efficiency increases with the increase of the orientation angle of the cubic baffle and with the decrease of the relative roughness pitch. We can therefore see that the combination of an orientation of $45^{\circ}$ with a roughness pitch of $\mathrm{b} / \mathrm{a}=2$ increases the SFAC thermal performances, which can reach $85 \%$.

In Figure 21 is represented the variation of the pressure drop with the Reynolds number for the different orientations with respect to the air flow for a roughness step equal to b/ $a=2$. It was seen that the pressure drop increases with Reynolds increases for the different configurations. The low values of the pressure difference are recorded for the configuration where the absorbent plate is smooth as long as the highest values are those of the configuration containing cubic baffles with $45^{\circ}$ orientation. These intense values are explained by the existence of tabulators compared to ordinary solar collectors which break the speed of air flow during flow and by the increase in the attack surface compared to other configurations.

In Figure 22 is represented the evolution of the mechanical pumping power defined as being the power necessary to ensure the uniformity of air flow along the solar collector cavity vs. the Reynolds number variation for the spherical and cubic configurations. The results show that the pumping power for the two configurations increases with Reynolds number increases. It was found the lowest power is obtained for a model without obstacles fixed on the absorber. It was also seen that for the same Reynolds value, the cube oriented $45^{\circ}$ requires greater pumping power than the other models. This result is explained by the large surface exposed directly to the air flow compared to the other orientations. This increase in surface increases the resistance which favors an increase in the pressure drop, hence a high power to maintain the flow uniformity. In Figure 23 is represented the 
TABLe 5: Positioning of the cubes in the solar collector.

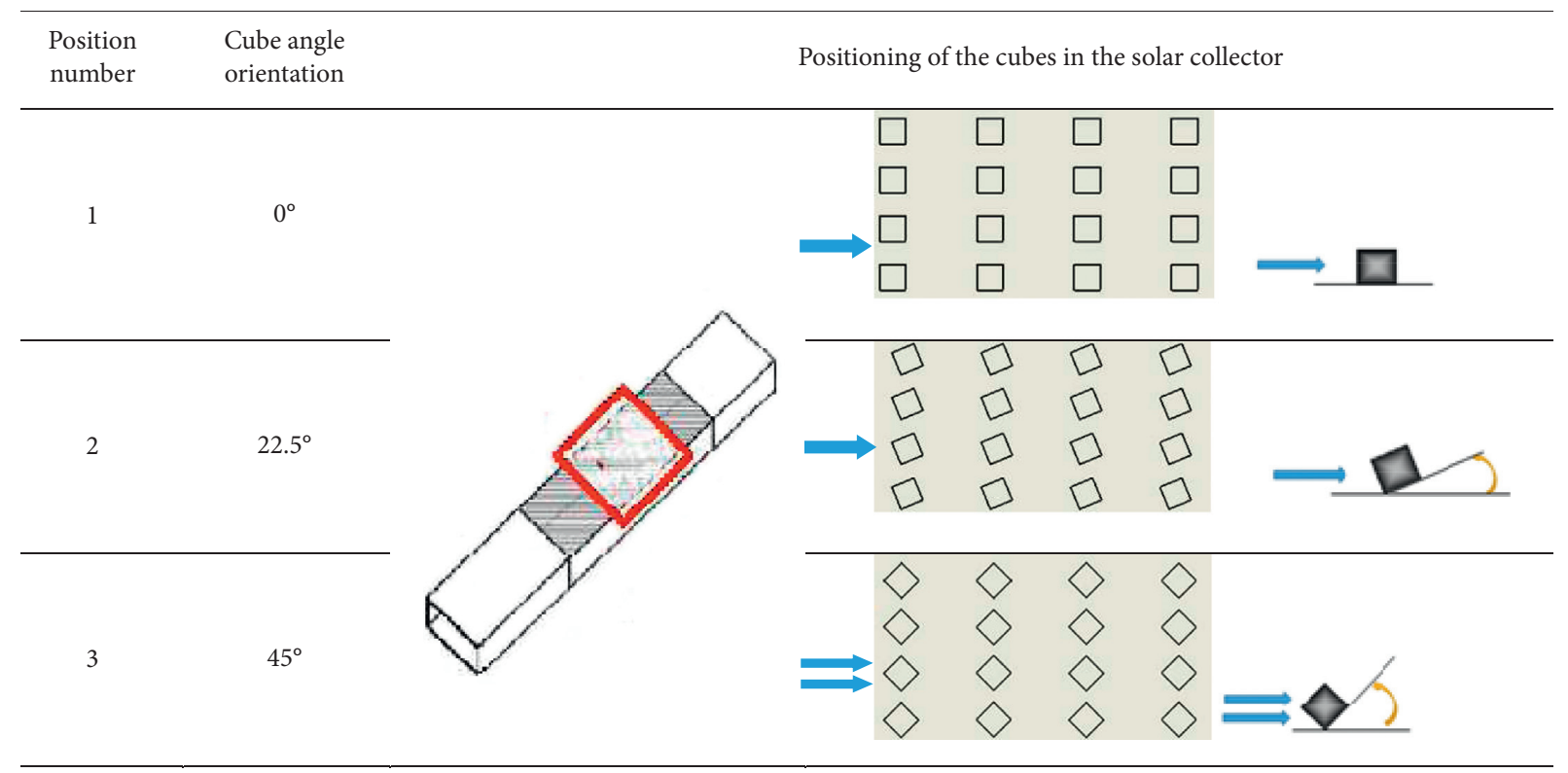

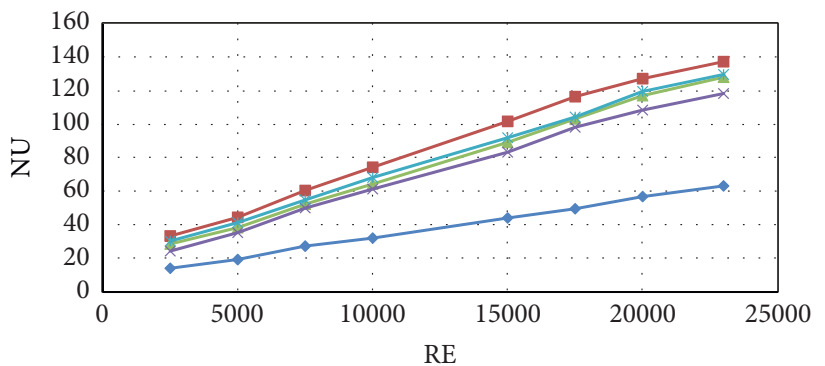

RE

$\rightarrow$ Ordinary solar collector

$\rightarrow$ Solar collector with cubic baffles : angle $45^{\circ}$

$\simeq$ Solar collector with cubic baffles : angle $22,5^{\circ}$

* Solar collector with cubic baffles : angle $0^{\circ}$

* Solar collector with spherical baffles

(a)

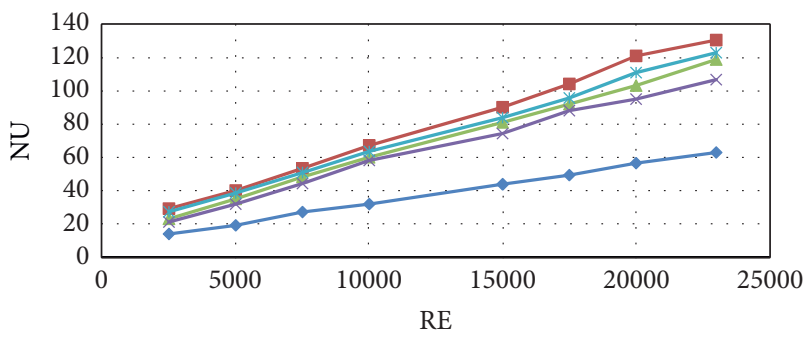

Ordinary solar collector

$\rightarrow$ Solar collector with cubic baffles : angle $45^{\circ}$

$\simeq$ Solar collector with cubic baffles : angle $22,5^{\circ}$

* Solar collector with cubic baffles : angle $0^{\circ}$

* Solar collector with spherical baffles

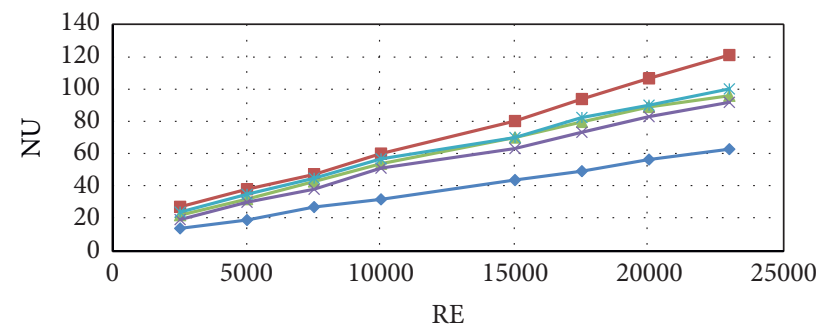

$\sim$ Ordinary solar collector

- - Solar collector with cubic baffles : angle $45^{\circ}$

- Solar collector with cubic baffles : angle $22,5^{\circ}$

* Solar collector with cubic baffles : angle $0^{\circ}$

* Solar collector with spherical baffles

(c)

Figure 16: Nusselt number of the five sensor configurations as a function of Reynolds for relative roughness pitches: (a) $b / a=2,(b) b / a=4$, and (c) $b / a=6$. 
Nuselt number

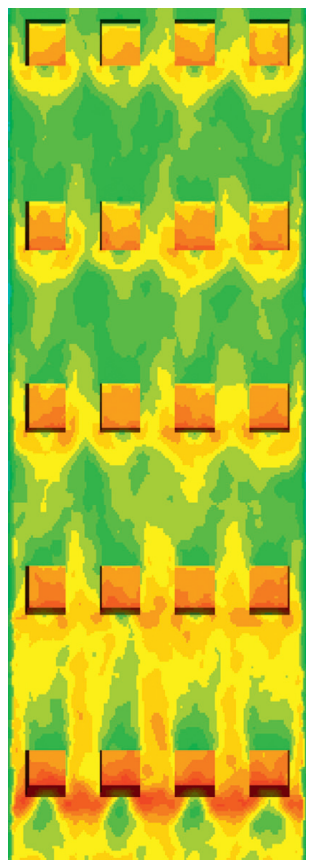

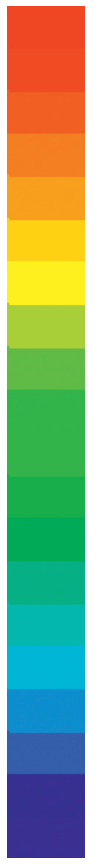

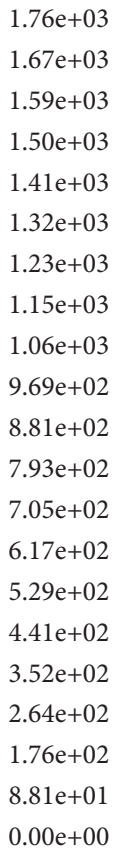

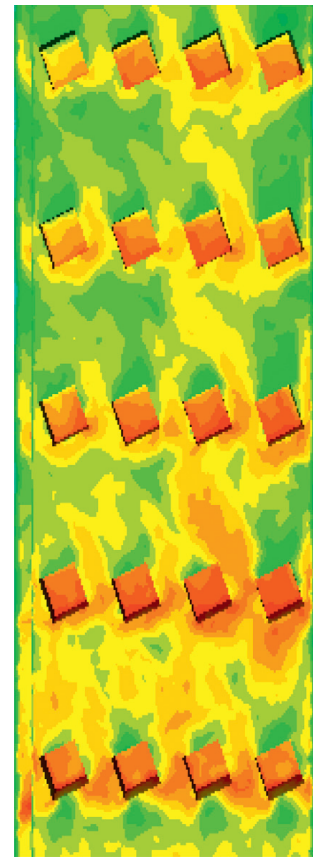

Nuselt number
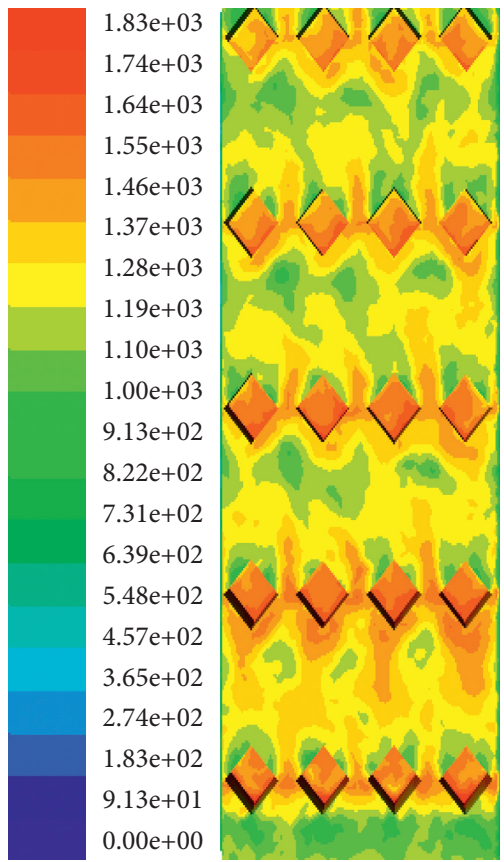

Nuselt number

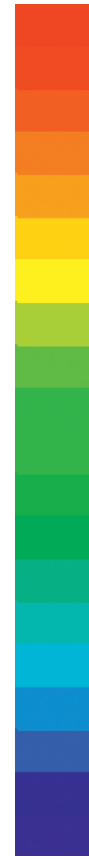

$1.93 \mathrm{e}+03$
$1.83 \mathrm{e}+03$
$1.73 \mathrm{e}+03$
$1.64 \mathrm{e}+03$
$1.54 \mathrm{e}+03$
$1.45 \mathrm{e}+03$
$1.35 \mathrm{e}+03$
$1.25 \mathrm{e}+03$
$1.16 \mathrm{e}+03$
$1.06 \mathrm{e}+03$
$9.64 \mathrm{e}+02$
$8.67 \mathrm{e}+02$
$7.71 \mathrm{e}+02$
$6.75 \mathrm{e}+02$
$5.78 \mathrm{e}+02$
$4.82 \mathrm{e}+02$
$3.86 \mathrm{e}+02$
$2.89 \mathrm{e}+02$
$1.93 \mathrm{e}+02$
$9.64 \mathrm{e}+01$
$0.00 \mathrm{e}+00$

FIGURE 17: Nusselt number variation imagery of the three configurations of three orientation angles (angle $0^{\circ}, 22.5^{\circ}$, and $45^{\circ}$ ) for a relative roughness pitch $\mathrm{b} / \mathrm{a}=2$ and a Reynolds number equal to 20000.

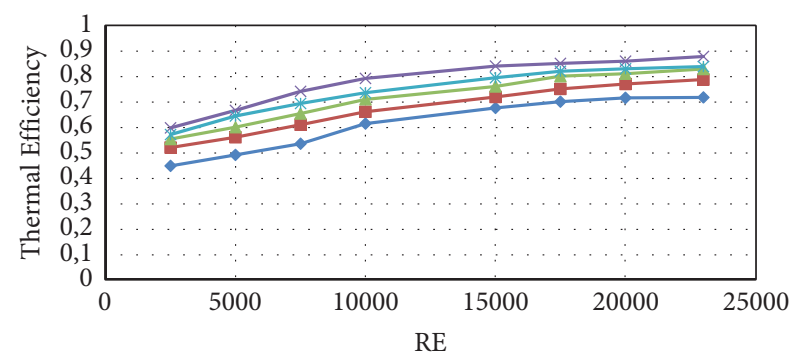

\footnotetext{
$\rightarrow$ Ordinary solar collector

$\rightarrow$ Solar collector with cubic baffles : angle $0^{\circ}$

$\leftarrow$ Solar collector with cubic baffles : angle $22,5^{\circ}$

$*$ Solar collector with cubic baffles : angle $45^{\circ}$

* Solar collector with spherical baffles
}

FIGURE 18: Thermal efficiency of the five solar collector configurations as a function of Reynolds for a relative roughness pitch b/ $\mathrm{a}=2$.

variation of the effective efficiency as a function of the Reynolds number. The results show that the maximum values of the effective efficiencies are as follows:

(i) Cube $\left(0^{\circ}\right)$ : a value of $69 \%$ for a $\operatorname{Re}=20000$

(ii) Cube $\left(22.5^{\circ}\right)$ : a value of $70 \%$ for a $\operatorname{Re}=17500$

(iii) Cube $\left(45^{\circ}\right)$ : a value of $76 \%$ for a $\operatorname{Re}=15000$

(iv) Sphere: a value of $72 \%$ for a $R e=15000$

It was found that the collector with cubic baffles having an orientation angle of $45^{\circ}$ is more efficient than the other solar collectors with cubic baffles having the orientation of $0^{\circ} 22.5^{\circ}$, respectively. It was also seen that cubic baffles

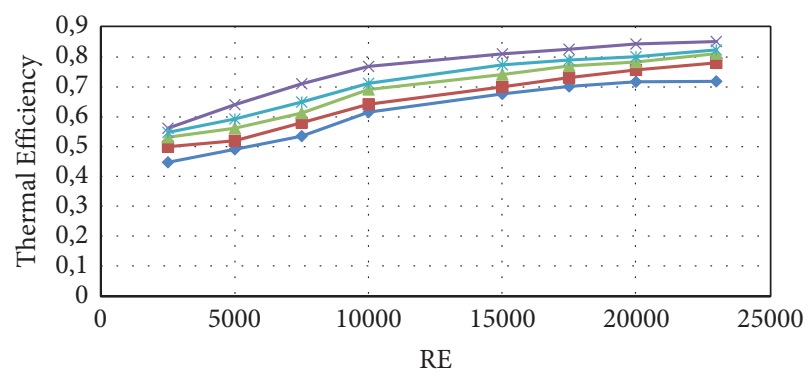

\footnotetext{
$\rightarrow$ Ordinary solar collector

$\rightarrow$ Solar collector with cubic baffles : angle $0^{\circ}$

$\rightarrow$ Solar collector with cubic baffles : angle $22,5^{\circ}$

* Solar collector with cubic baffles : angle $45^{\circ}$

* Solar collector with spherical baffles
}

Figure 19: Thermal efficiency of the five solar collector configurations as a function of Reynolds for a relative roughness pitch b/ $\mathrm{a}=4$.

having an orientation angle of $45^{\circ}$ are more effective than the spherical baffles. It can be added that the importance of achieving effective efficiency for a lower Reynolds number is keeping the solar collector inertia for a long time.

4.5. Effects of Reynolds Number on Performance. In order to study the impact of the Reynolds number on performance, we represent in Figure 24 the variation of thermal efficiency as well as $(\mathrm{Pm} / \mathrm{C} * \mathrm{~S} * \mathrm{I})$ vs. the Reynolds number variation for a relative roughness pitch $b / a=2$. It was found that for high Reynolds numbers, the rate of increase in mechanical pumping power is very significant, while the rate of thermal 


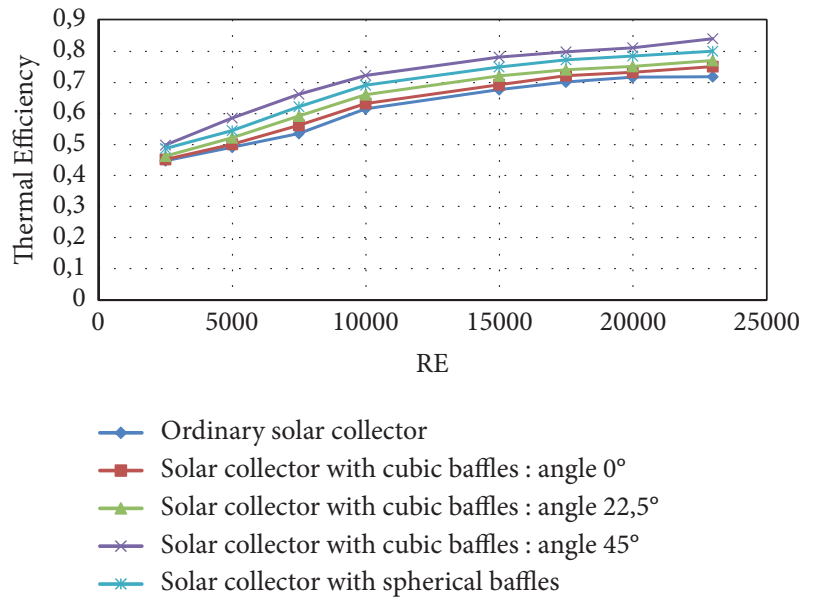

Figure 20: Thermal efficiency of the five solar collector configurations as a function of Reynolds for a relative roughness pitch b/ $\mathrm{a}=6$.
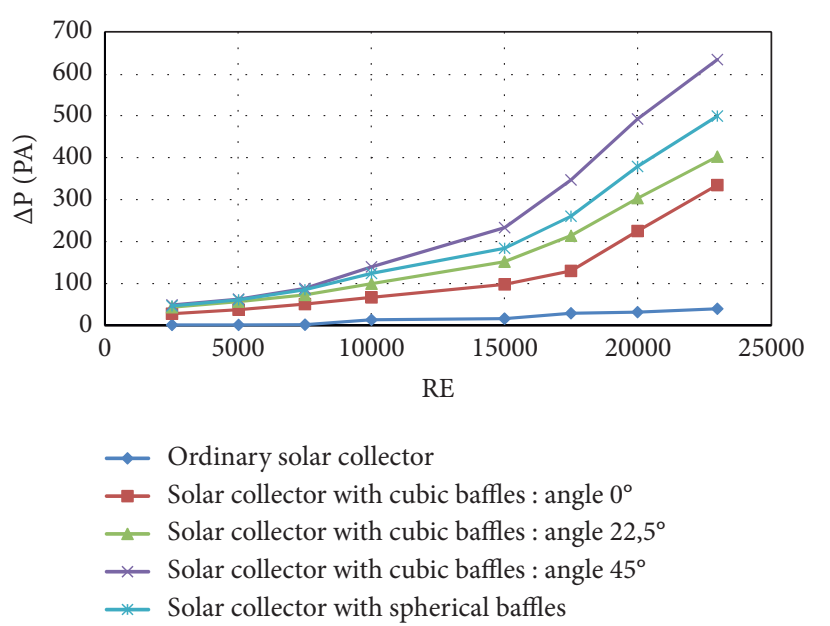

Figure 21: Pressure drop as a function of the Reynolds number for a relative roughness pitch $\mathrm{b} / \mathrm{a}=2$.

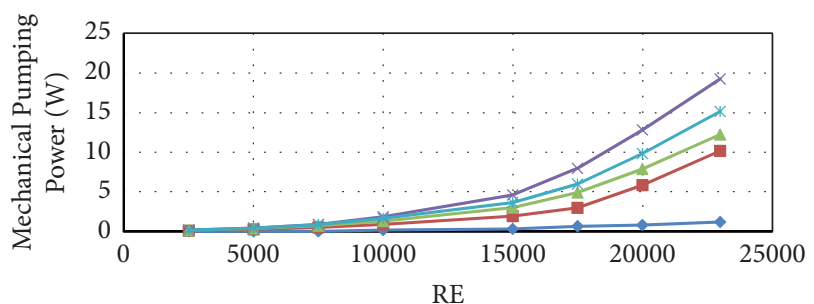

$\rightarrow$ Ordinary solar collector

$\rightarrow$ Solar collector with cubic baffles : angle $0^{\circ}$

$\rightarrow$ Solar collector with cubic baffles : angle $22,5^{\circ}$

* Solar collector with cubic baffles : angle $45^{\circ}$

* Solar collector with spherical baffles

FIGURE 22: Mechanical pumping power vs the Reynolds number for a relative roughness pitch $\mathrm{b} / \mathrm{a}=2$.

efficiency becomes almost constant. On the other hand, for low Reynolds numbers, the rate of increase in mechanical pumping power, necessary to keep the air flow constant, is

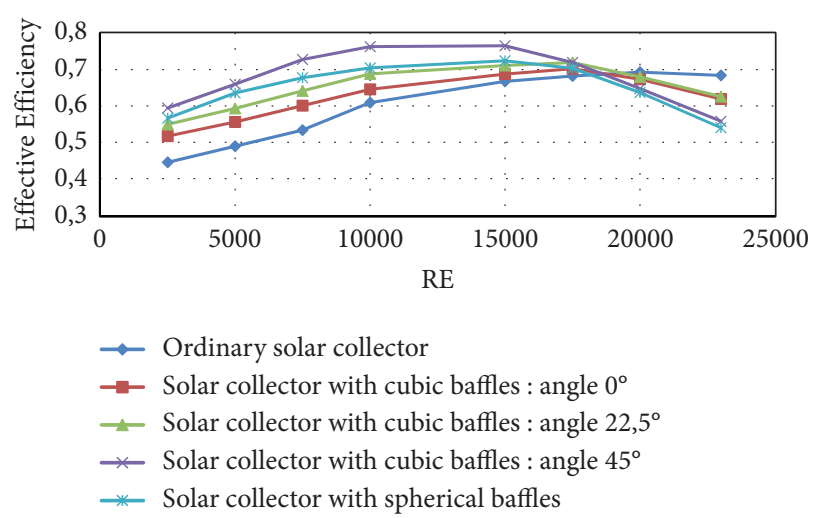

FIGURE 23: Effective efficiency vs the Reynolds number for a relative roughness pitch $\mathrm{b} / \mathrm{a}=2$.

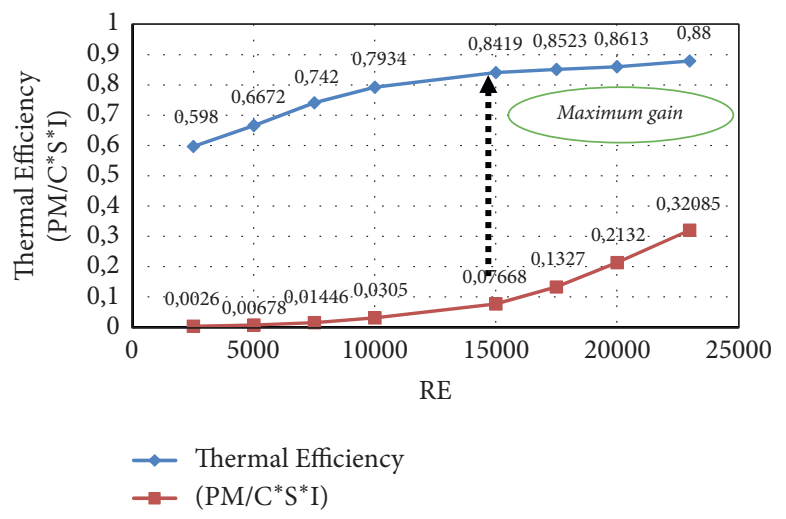

Figure 24: Thermal efficiency, $(\mathrm{Pm} / \mathrm{C} * \mathrm{~S} * \mathrm{I})$ vs the Reynolds number for a relative roughness pitch $\mathrm{b} / \mathrm{a}=2$.

low, while the rate of thermal efficiency is important. Between these two extremes of the Reynolds number, we can reach a stage where we obtain the optimal value of the energy gain measures of $76 \%$ for a Reynolds number equal to 15 000. Figure 24 also shows that for a large Reynolds number value, the net energy gain disappears and decreases towards lower values contrary to the desired values. Consequently, as a summary of this treatment, we can limit the Reynolds value to 15000 for the correct functioning of the solar collector.

\section{Conclusions}

In this paper, we present a numerical study using the CFD software to perform a special air solar collector configuration of the most famous baffles (spheres, cubes, cylinders, and pyramids) to fix on the absorber of the SFAC by developing a parametric optimization and investigation by defining a geometric form of an orientation angle. The study was carried out for different relative roughness pitches b/a equal to 2,4 , and 6 for a turbulent regime $2500 \leq \mathrm{Re} \leq 20000$. To validate the results of the simulations carried out in our model, we have chosen the results of a publication by Manjunath et al. It was found that our model with the imposed limiting conditions can reproduce the results of Manjunath et al. Then, we exploited our developed model in the optimization of the different arrangements and 
configurations in order to obtain the most appropriate and feasible Solar Flat Air Collector (SFAC).

In this paper, we have also investigated the obstacle geometries and arrangements effects on air flow inside the SFAC air cavity. In this context, a simulation based on the most adapted configuration that can create more turbulence inside the SFAC air cavity was performed. To highlight the SFAC with a cubic obstacles configuration, another numerical simulation was proposed. It studied the effect of the cubic obstacles on the air flow inside the SFAC air cavity. The results of the simulation also showed that inside a cavity containing cubic obstacles, we can observe the creation of turbulence in the vicinity of the obstacles which makes the medium homogeneous and cancels the dead zones inside the air cavity of the solar collector. We have also studied the effect of the relative roughness pitch (b/a) on the Nusselt numbers. It was found that the Nusselt number increases as a function of the Reynolds number. The simulation showed that the turbulence fluctuate remarkably depending on the position inside the solar collector cavity. We have also studied the configurations and the arrangement of the obstacles effects on the thermal efficiency variation of the SFAC. The impact on the pressure drop for the different SFAC configurations was also investigated in this paper. It was showed that during the air-flow circulation, the initial pressure increases with the Reynolds number increasing. A simulation of the Nusselt number variation for the spherical and the cubic obstacles configuration is carried out. The simulation is achieved for a relative roughness pitches equals to $\mathrm{b} / \mathrm{a}=2,4$, and 6 , respectively. The simulation showed that the Nusselt value for the configuration which contains cubes obstacles with $45^{\circ}$ orientation and with a roughness pitch b/ $\mathrm{a}=2$ is more important compared to the other configurations studied, even those which contain spheres. The effect of the cubic obstacle angle orientation on the Nusselt number variation for a relative roughness pitch equal to $b / a=2$ and a flow rate that corresponds to a Reynolds number equal to 23000 was also studied. It was showed that with an orientation of $45^{\circ}$ and with a roughness pitch of $\mathrm{b} / \mathrm{a}=2$, the thermal efficiency can exceed $85 \%$.

We conclude that SFAC contains cubes obstacles with $45^{\circ}$ orientation and with a roughness pitch $\mathrm{b} / \mathrm{a}=2$ confers a promising solution to enhance the solar collector performances. It is obvious that further studies on SFAC applications in Tunisian households are necessary. The results of this investigation will be accompanied with economic study to highlight the SFAC configuration and arrangement.

\section{Nomenclature}

$$
\begin{array}{ll}
b / a: & \text { Relative roughness pitch } \\
C_{p}: & \text { Specific heat, } \mathrm{J} / \mathrm{KgK} \\
C_{\varepsilon 1}, C_{\varepsilon 2}, C_{\varepsilon 1}: & \text { Constants of the } k-\varepsilon \text { réalisable model } \\
D_{h}: & \text { Hydraulic diameter, } \mathrm{m} \\
\vec{f}: & \text { Gravity force, } \mathrm{m} / \mathrm{s}^{2} \\
h: & \text { Specific enthalpy, } / \mathrm{kg} \\
I: & \text { Radiation intensity, } \mathrm{W} / \mathrm{m}^{2} \\
K: & \text { Thermal conductivity, } \mathrm{W} / \mathrm{m} . \mathrm{K} \\
k: & \text { Turbulent kinetic energy, } \mathrm{J} / \mathrm{Kg}
\end{array}
$$

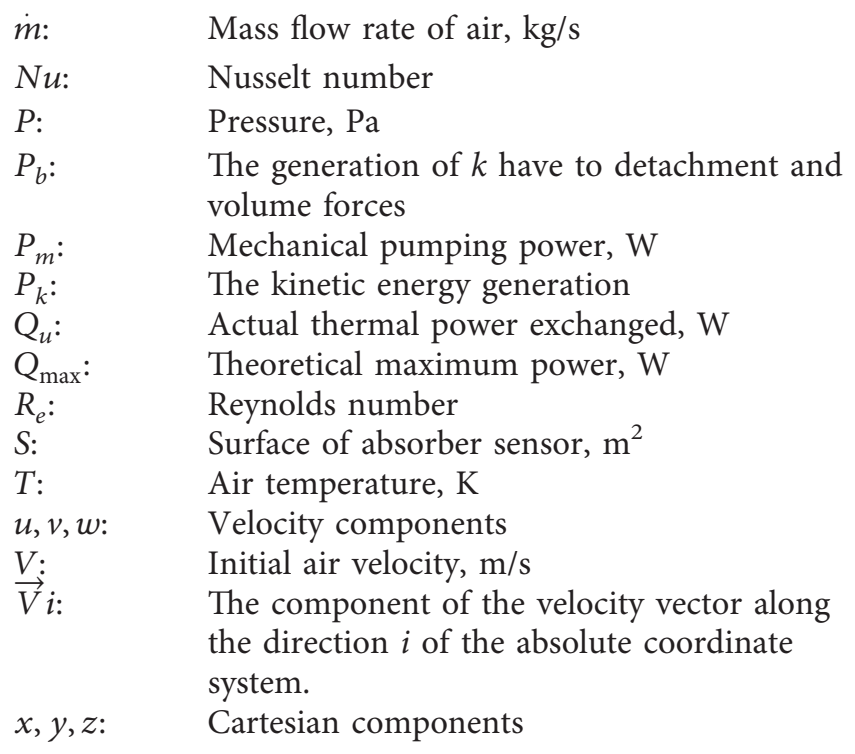

\section{Greek symbols}

$\Delta P: \quad$ Pressure drop over the length of the test section, $\mathrm{Pa}$

$\eta_{\text {ther }}:$ Thermal efficiency (\%)

$\eta_{\text {eff }}$ : Effective efficiency

$\tau: \quad$ Viscous strain tensor

$\varepsilon$ : Kinetic energy dissipation

$\sigma k$ : Nombres de Prandtl turbulent associés à $k$.

$\sigma \varepsilon: \quad$ Nombres de Prandtl turbulent associés à $\varepsilon$

$\rho: \quad$ Density of air, $\mathrm{Kg} / \mathrm{m}^{3}$

$\mu$ : Dynamic viscosity, $\mathrm{Kg} / \mathrm{ms}$.

\section{Data Availability}

The data used to support the findings of this article were constituted by authors mentioned in the paper. Also, all the data are included within the article and no external data were used to support this study.

\section{Conflicts of Interest}

The authors declare that they have no known conflicts of interest or personal relationships that could have appeared to persuade the work reported in this paper.

\section{Acknowledgments}

The authors would like to thank the Laboratoire des Procédés Thermiques (LPT) and the Centre de Recherches et des Technologies de l'Energie (CRTEn), Tunis, Tunisia for financially supporting the project and for supplying useful data.

\section{References}

[1] A. Ahmed-Zaid, H. Messaoudi, A. Abenne, M. Le Ray, J. Y. Desmons, and B. Abed, "Experimental study of thermal performance improvement of a solar air flat plate collector through the use of obstacles: application for the drying of "yellow onion"," International Journal of Energy Research, vol. 23, no. 12, pp. 1083-1099, 1999. 
[2] A. Khanlari, H. Ö. Güler, A. D. Tuncer et al., "Experimental and numerical study of the effect of integrating plus-shaped perforated baffles to solar air collector in drying application," Renewable Energy, vol. 145, pp. 1677-1692, 2020.

[3] N. Y. Sharma, N. Madhwesh, and K. V. Karanth, "The effect of flow obstacles of different shapes for generating turbulent flow for improved performance of the solar air heater," Procedia Manufacturing, vol. 35, pp. 1096-1101, 2019.

[4] S. Sompol, P. Promvonge, C. Thianpong, and M. Pimsarn, "Thermal performance in solar air heater channel with combined wavy-groove and perforated-delta wing vortex generators," Applied Thermal Engineering, vol. 100, pp. 611620, 2016.

[5] A. Doğuş Tuncer, A. Sözenc, A. Khanlari, A. Ali, and C. Şirin, "Thermal performance analysis of a quadruple-pass solar air collector assisted pilot-scale greenhouse dryer," Solar Energy, vol. 203, pp. 304-316, 2020.

[6] S. Singh, "Thermohydraulic performance of double pass solar thermal collector with inline, staggered and hybrid fin configurations," Journal of Energy Storage, vol. 27, p. 101080, 2020.

[7] J. Hu, X. Sun, J. Xu, and Z. Li, "Numerical analysis of mechanical ventilation solar air collector with internal baffles," Energy and Buildings, vol. 62, pp. 230-238, 2013.

[8] F. Afshari, A. Sözen, A. Khanlari, A. D. Tuncer, and C. Şirin, "Effect of turbulator modifications on the thermal performance of cost-effective alternative solar air heater," Renewable Energy, vol. 158, pp. 297-310, 2020.

[9] A. Sözen, C. Șirin, A. Khanlari, A. D. Tuncer, and E. Y. Gürbüz, "Thermal performance enhancement of tubetype alternative indirect solar dryer with iron mesh modification," Solar Energy, vol. 207, pp. 1269-1281, 2020.

[10] K. A. Ebru and K. Fatih, "Experimental investigation of thermal performance of solar air heater having different obstacles on absorber plates," International Communications in Heat and Mass Transfer, vol. 37, pp. 416-421, 2010.

[11] W. Zheng, H. Zhang, S. You, Y. Fu, and X. Zheng, “Thermal performance analysis of a metal corrugated packing solar air collector in cold regions," Applied Energy, vol. 203, pp. 938-947, 2017.

[12] A.-M. Ebrahim Momin, J. S. Saini, and S. C. Solanki, "Heat transfer and friction in solar air heater duct with V-shaped rib roughness on absorber plate," International Journal of Heat and Mass Transfer, vol. 45, no. 16, pp. 3383-3396, 2002.

[13] A. Kumar, J. L. Bhagoria, and R. M. Sarviya, "Heat transfer and friction correlations for artificially roughened solar air heater duct with discrete W-shaped ribs," Energy Conversion and Management, vol. 50, no. 8, pp. 2106-2117, 2009.

[14] V. S. Hans, R. P. Saini, and J. S. Saini, "Heat transfer and friction factor correlations for a solar air heater duct roughened artificially with multiple V-ribs," Solar Energy, vol. 84, no. 6, pp. 898-911, 2010.

[15] S. K. Saini and R. P. Saini, "Development of correlations for Nusselt number and friction factor for solar air heater with roughened duct having arc-shaped wire as artificial roughness," Solar Energy, vol. 82, no. 12, pp. 1118-1130, 2008.

[16] A. Lanjewar, J. L. Bhagoria, and R. M. Sarviya, "Heat transfer and friction in solar air heater duct with W-shaped rib roughness on absorber plate," Energy, vol. 36, no. 7, pp. 4531-4541, 2011.

[17] B. N. Prasad, "Thermal performance of artificially roughened solar air heaters," Solar Energy, vol. 91, pp. 59-67, 2013.

[18] M. S. Manjunath, K. Vasudeva Karanth, and N. Yagnesh Sharma, "Numerical investigation on heat transfer enhancement of solar air heater using sinusoidal corrugations on Ab-sorber plate," International Journal of Mechanical Sciences, vol. 138-139, 2018.

[19] M. S. Manjunath, K. V. Karanth, and N. Y. Sharma, "Numerical analysis of the influence of spherical turbulence generators on heat transfer enhancement of flat plate solar air heater," Energy, vol. 121, pp. 616-630, 2017.

[20] A. Cortés and R. Piacentini, "Improvement of the efficiency of a bare solar collector by means of turbulence promoters," Applied Energy, vol. 36, no. 4, pp. 253-261, 1990.

[21] M. K. Mittal and L. Varshney, "Optimal thermohydraulic performance of a wire mesh packed solar air heater," Solar Energy, vol. 80, no. 9, pp. 1112-1120, 2006.

[22] J. L. Bhagoria, J. S. Saini, and S. C. Solanki, "Heat transfer coefficient and friction factor correlations for rectangular solar air heater duct having transverse wedge shaped rib roughness on the absorber plate," Renewable Energy, vol. 25, no. 3, pp. 341-369, 2002.

[23] 1991 Simulation of compressible turbulent flows by a mixed finite element-finite volume method catherine le ribault.

[24] P. J. Roache, Computational Fluid Dynamics, Hermosa Publishers, Albuquerque, NM, USA, 1985.

[25] V. Yakhot and S. A. Orszag, "Renormalization group Analysis of turbulence: 1. Basic theory," Journal of Scientific Computing, vol. 4, pp. 139-158, 1986.

[26] J. Mattei, Modélisation Analytique et Numérique de la Cavité Interne d'un Injecteur Rotatif Fronde Pour Turbine a Gaz, Université Laval, Quebec, Canada, 2010.

[27] H. T. Shih, W. W. Liou, A. Shabbir, Z. Yang, and J. Zhu, “A new $k-\varepsilon$ Eddy viscosity model for high Reynolds number turbulent flows. model development and validation," Computers Fluids, vol. 24, no. 3, pp. 227-238, 1995.

[28] R. Kumar, A. Kumar, and A. Goel, "Performance improvement and development of correlation for friction factor and heat transfer using computational fluid dynamics for ribbed triangular duct solar air heater," Renewable Energy, vol. 131, pp. 788-799, 2019.

[29] A. R. Jaurker, J. S. Saini, and B. K. Gandhi, "Heat transfer and friction characteristics of rectangular solar air heater duct using rib-grooved artificial roughness," Solar Energy, vol. 80, no. 8, pp. 895-907, 2006.

[30] M. Aktas, S. Sevik, A. Ali, and A. Khanlari, "Analysis of drying of melon in a solar-heat recovery assisted infrared dryer," Solar Energy, vol. 137, pp. 500-515, 2016.

[31] A. L. Antony, S. P. Shetty, N. Madhwesh, N. Yagnesh Sharma, and K. Vasudeva Karanth, "Influence of stepped cylindrical turbulence generators on the thermal enhancement factor of a flat plate solar air heater," Solar Energy, vol. 198, pp. 295-310, 2020. 